POTENTIAL USE OF ULTRAVIOLET RADIATION

FOR THE CONTROL OF ZEBRA MUSSELS

PHASE I - LAB STUDIES

PHASE II - FIELD TRIALS

RAC Project No. 598C

FINAL REPORT

MINISTRY OF ENVIRONMENT AND ENERGY

(8) Ontario 
ISBN 0-7778-3199-6

POTENTIAL USE OF ULTRAVIOLET RADIATION

FOR THE CONTROL OF ZEBRA MUSSELS

PHASE I - LAB STUDIES

PHASE II - FIELD TRIALS

RAC Project No. 598C

FINAL REPORT

Report prepared by:

Aquatic Science Inc.

St. Catharines, Ontario

ASI Project \#M9411

OCTOBER 1995

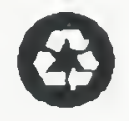

Cette publication technique n'est disponible qu'en anglais. Copyright: Queen's Printer for Ontario, 1995

This publication may be reproduced for non-commercial purposes with appropriate attribution.

PIBS 3381 



\section{ACKNOWLEDGEMENT AND DISCLAIMER}

This report was prepared for the Ontario Ministry of Environment and Energy and the Ontario Ministry of Natural Resources. The views expressed in this report are those of the author and do not necessarily reflect the views and policies of the Ministry of Environment and Energy or the Ministry of Natural Resources, nor does mention of trade names or commercial products constitute endorsement or recommendation for use. The Ministries, however, encourage the distribution of information and strongly support technology transfer and diffusion.

Any person who wishes to republish part or all of this report should apply for permission to do so to the Environmental Research Program, Science and Technology Branch, Ontario Ministry of Environment and Energy, 2 St. Clair Avenue West, 14th Floor, Toronto, Ontario, Canada, M4V 1 P5. 


\section{TABLE OF CONTENTS}

1.0) EXECUTIVE SUMMARY

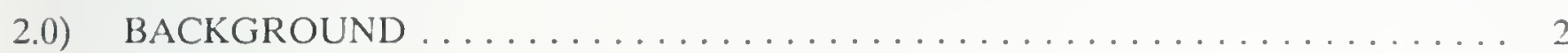

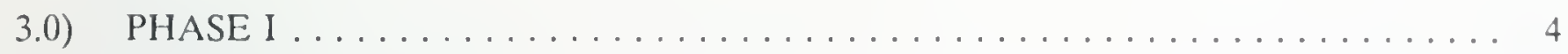

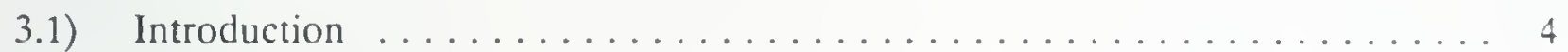

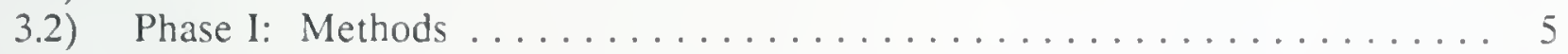

3.3) Phase I: Results and Discussion ................... 7

3.3.1) UV Transmission ........................ 7

3.3.2) Veligers ............................. 7

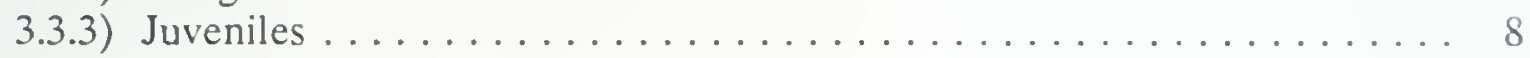

3.4) Phase I: Conclusions ........................ 9

4.0) PHASE II: FLOW THROUGH FIELD STUdiES $\ldots \ldots \ldots \ldots \ldots \ldots \ldots \ldots$

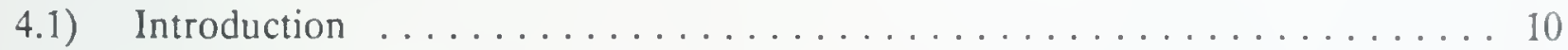

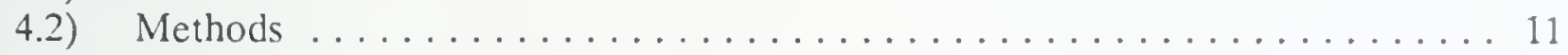

4.3) Phase II Flow Through Field Studies: Results and Discussion . . . . . . . 13

4.3.1) UV Transmission . . . . . . . . . . . . . . . . 13

4.3.2) Sample Analysis ........................... 14

4.3.2.1) Single Lamp - Low Pressure Unit $(254 \mathrm{~nm}) \quad \ldots \ldots \ldots 14$

4.3.2.2) Multiple Lamp - Low Pressure System (254 nm) ..... 16

4.3.2.3) Open Channel - Low Pressure System (254 nm) ..... 17

4.3.2.4) Single Lamp - Medium Pressure System $(365 \mathrm{~nm}) \ldots . .18$

4.3.3) Post Study Tank Wall and Culture Plate Settlement . . . . . . . . . . . 20

4.3.3.1) Single Lamp - Low Pressure System . . . . . . . . . 20

4.3.3.2) Multiple Lamp - Low Pressure System . . . . . . . . 21

4.3.3.3) Open Channel - Low Pressure System .......... 21

4.3.2.4) Single Lamp - Medium Pressure System . . . . . . . . 22

4.3.2.5) Five Day Sediment Analysis . . . . . . . . . 22

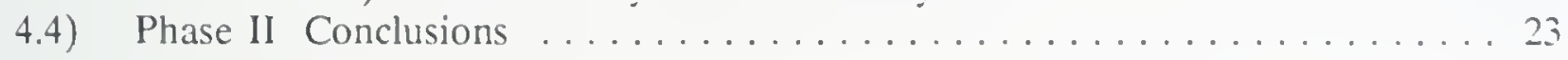

5.0) RECOMMENDATIONS ................................ 25

APPENDIX I Effect of UV Irradiation of Heterotrophic Microorganisms 


\section{USE OF ULTRAVIOLET RADIATION FOR ZEBRA MUSSEL CONTROL}

D. Lewis; Aquatic Sciences Inc., St. Catharines, Ontario, and Dr. G.E. Whitby; Fischer and Porter (Canada) Inc., Downsview, Ontario

\section{0) EXECUTIVE SUMMARY}

The use of chemical oxidants, particulary chlorine, has been wide spread for the control of zebra mussel infestations in both the United States and Canada.

These treatments appear to have been very effective, however, there are many reasons why the search for alternate strategies continues. These include the potential formation of chlorination byproducts which may be damaging to the aquatic environment or human health, along with the potential for over chlorination or spills posing a risk to aquatic life in the vicinity of outfalls.

The move to alternative oxidants or other potentially toxic materials does not appear to be wise due to potential long term environmental concerns. These products may be more damaging than chlorine, which is in wide use today. It follows that new control measures should focus on nonchemical solutions or at least be useful in reducing the use of chemicals.

Ultraviolet light is used throughout the world for the disinfection of air, water and surfaces. UV light has recently become popular for the disinfection of municipal wastewater, as the ability to treat larger volumes of water has become available.

Phase I of this research consisted of work with both veligers and juvenile zebra mussels in batch tests. That work was designed to allow determination of the most effective treatment protocols using UV technology and to develop appropriate test protocols for field trials. 


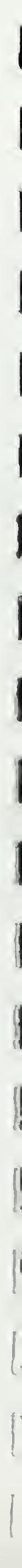


The results of Phase I showed that two types of lamp systems incorporating UVC (254 nm) and UVB/UVC (200-400 nm) combinations would provide some level of protection. However, Phase I appeared to indicate that only very low flows could be treated with UV light.

Phase II involved development of flow-through tests that allowed in-line tests with four different treatment configurations

These systems consisted of two closed pipe systems using UVC wavelengths, one closed pipe system using UVC/UVB combinations and one open channel system using a UVC wavelength.

All the test systems were effective in preventing settlement of zebra mussels in test chambers. High latent mortalities (30 minutes for 90-100\%), were also observed routinely in collected water samples.

This study provides convincing evidence that UV light can be used for the prevention of zebra mussel infestation for low volume water users and shows promise that larger volume treatment systems could be developed for large flows. It is also interesting to note that the use of UV systems for treatment of ships ballast water may soon be available, which could help prevent further introduction of this nature.

\section{0) BACKGROUND}

Ultraviolet light is commonly used in hospitals and the food industry for disinfecting air.or process water and has become popular, on a small scale, as a disinfecting agent for potable water or recreational pools.

More recently, the ability to treat larger volumes of water has led to the promotion of UV disinfection at all types of water pollution control plants (WPCP). Almost 1,000 systems are in place and UV has become accepted as a viable alternative technology to chlorination. While water quality can affect the ability to effectively treat water with $U V$, there are many instances where a change in UV technology has proven successful. 
It is also known that naturally occurring ultraviolet radiation can effect the behaviour and physiology of planktonic larvae and may be a limiting factor to zooplankton communities.

There are many water users which do not have the ability or the inclination to use chlorine to control zebra mussels. This may be due to the additional costs of dechlorination, concerns with meeting the Ontario Ministry of the Environment and Energy's effluent requirements or a variety of other previously listed environmental concerns. Many of these users may be able to take advantage of already established methodologies to retrofit their systems with UV radiation equipment.

For many groups, zebra mussel reproduction corresponds directly with peak water volume use. This is particularly true of seasonal operations such as greenhouses, golf courses, resorts or commercial shipping operations.

Early stages of zebra mussel development may be vulnerable to UV radiation. Veliger larvae are transparent or translucent until they reach the settling stage. It was felt that UV radiation would likely be effective for the control of larval mussels, which lack the pigments to protect their vital organs. Wavelengths and power levels need to be determined in order to build full scale UV systems.

In addition to the problem of veliger settlement, a new phenomenon has recently been described, whereby significant numbers of small juvenile mussels may detach from their original substrate and reenter the water column. This appears to be a year round activity. These mussels (translocators) are increasingly being thought of as a threat should they be small enough to pass through screens and coarse filters and into service water systems where they may settle again and grow. The effect of UV radiation against this size class also needed to be established to determine whether it can be used as a means of protecting service water systems alone and at what age juveniles become resistant to this treatment. 


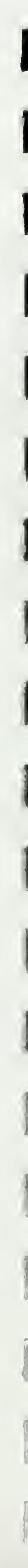




\section{0) PHASE I \\ 3.1) Introduction}

In a single preliminary study, Ontario Hydro provided evidence that a flow through UV system using a single low pressure mercury lamp would prevent the downstream settlement of zebra mussels, (per comm Renata Claudi, Ontario Hydro). The dose of UV light needed to prevent settlement and the mechanism by which this was achieved was not investigated.

The project at hand was designed to provide the information needed to further elaborate on the potential of UV for zebra mussel control. The project was divided into two phases. Phase I involved laboratory batch tests while Phase II involved small scale flow-through systems to determine the feasibility of using UV in flowing systems.

The first phase of this project was designed to determine the dose of UV light required to kill the various stages of the zebra mussels and which UV wavelengths were most effective.

Low pressure mercury lamps produce all UV light at a wavelength of $254 \mathrm{~nm}$ (UVC). This wavelength is readily absorbed by organic compounds in the water, and hence can result in significant attenuation in organic waters. This wavelength may also be readily absorbed by the surface cells or shell of the mussels at their various stages of development which would further prevent destruction of the genetic material which is the primary target of UV light at $254 \mathrm{~nm}$.

Medium pressure mercury lamps produce a significant amount of UV light at a wavelength of 365 nm (UVB). UV light at this wavelength is not absorbed as readily by compounds in the water and may be more effective at killing zebra mussels. These longer UV wavelengths will destroy biological tissues.

Both low and medium pressure mercury lamps were tested simultaneously to determine the optinum wavelengths from a commercially available UV lamp. Figure 1 shows a comparison of the lamp's wavelengths. 


To size the flow through UV systems for Phase II, the UV dose must be known. The UV dose is defined as:

Dose $=$ Intensity $\times$ Time

$\begin{array}{lll}\text { where } & \text { Dose }= & \text { Watt } \mathrm{sec} / \mathrm{cm}^{2} \\ \text { Intensity } & =\quad \mathrm{W} / \mathrm{cm}^{2} \\ \text { Time }= & \text { seconds }\end{array}$

In a flow through UV system, it is very difficult to accurately determine the UV intensity and the exposure time. The method of Qualls and Johnson (1983) was modified in this study to expose batches of mussels at various stages of development to known doses of UV light. This method uses a parallel beam of UV light which can be measured accurately and uses a shutter to control the exposure time.

\section{2) Phase I: Methods}

During the late summer and fall of 1992 veligers and juvenile zebra mussels were obtained from the headworks of Ontario Hydro's Decew Hydro Electric facility in St. Catharines Ontario, Canada. Veliger tests were run in duplicate using 200-1,000 veligers per sample depending on the availability. Juvenile tests were run in triplicate using 100-300 individuals per sample. Juveniles were irradiated in groups according to size and species. Both zebra mussels and newly discovered quagga mussels were exposed in groups at $1,2,3$ and $5 \mathrm{~mm}$ lengths.

Test organisms were put in a water filled, $2 \frac{1 / 4}{4} \times 1 \frac{114}{4}$ inch, petri dish which was placed in the collimated beam apparatus as shown in Figure 2. Two identical test systems were set up adjacent to each other. A low pressure mercury lamp was positioned on one side of the apparatus and a medium pressure mercury lamp on the opposite side. The UV intensity was measured at a wavelength of $254 \mathrm{~nm}$ at the surface of the stirred vessel with a TL 1700 Radiometer with an SEE 240 probe. The low pressure mercury lamp was adjusted to $500 \mu \mathrm{W} / \mathrm{cm}^{2}$ and the medium pressure mercury lamp was adjusted to $500 \mu \mathrm{W} / \mathrm{cm}^{2}$. 



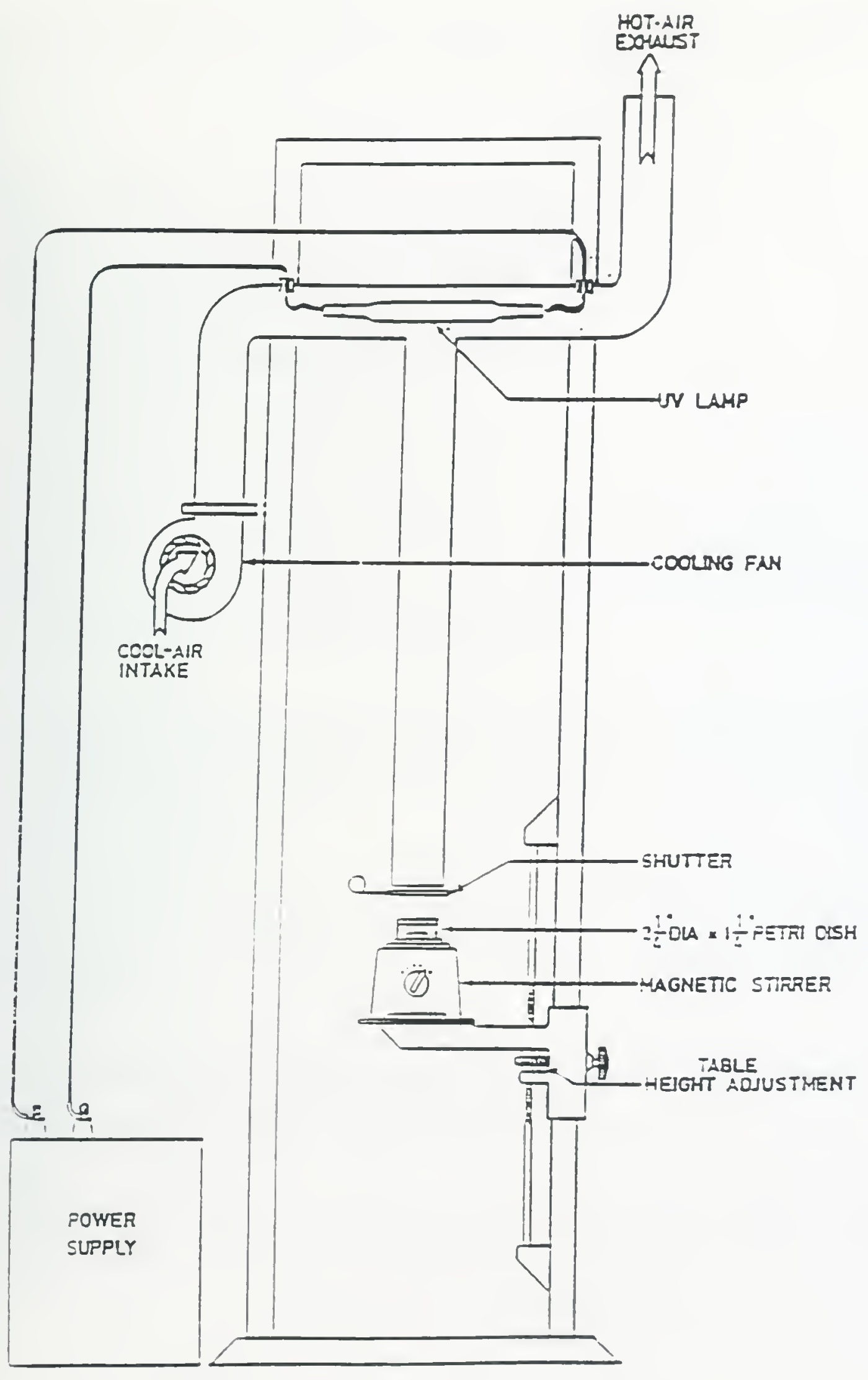

Figure 2: Schematic diagram ot the collimated beam apparatus for tradarang the varsous wastewaters. 

The average UV intensity within the reaction vessel was calculated by using the following equation:

$$
\begin{array}{ll}
\mathrm{I}= & \mathrm{I}_{\mathrm{o}}\left(1-\mathrm{e}^{\mathrm{cd}} / \mathrm{cd}\right) \\
\text { where I } & =\text { adjusted UV average UV intensity } \\
& \mathrm{I}_{0} \quad=\mathrm{UV} \text { intensity at the liquid surface in } \mu \mathrm{W} / \mathrm{cm}^{2} \\
\mathrm{~d} & =\text { fluid depth in centimetres } \\
\mathrm{c} & =\text { absorbance coefficient to the base } \mathrm{e}
\end{array}
$$

\begin{abstract}
All of the UV doses are relative to a wavelength of $254 \mathrm{~nm}$. Actual intensity of other wavelengths was not measured. Any increased kill by the medium pressure mercury lamp is due to other UV wavelengths. Samples were continuously stirred with a magnetic stirring bar so that each organism was exposed to the average dose of UV light. Control samples which were stirred but not exposed to the UV light source were also measured for mortality.
\end{abstract}

Periodically during the study, the UV transmission of the water was measured in a $1 \mathrm{~cm}$ quartz cuvette at a wavelength of $254 \mathrm{~nm}$ and $365 \mathrm{~nm}$ using a Beckman Spectrophotometer. Distilled water was used as a blank.

Trial runs for the medium pressure lamp were completed at exposure times of 15 minutes, 1 hour, 2 hours and 3 hours. The exposure times for the low pressure mercury lamp were 1 hour, 2 hours, 3 hours and 4 hours.

Due to the heat produced by the medium pressure mercury lamp, a series of tests were run using an ice bath to maintain the samples at an ambient temperature of $20^{\circ} \mathrm{C}$.

Mortalities were determined by observing visceral and cilial movement under a microscope at a magnification of 80 times immediately following the trial. No latent mortality determinations were made. 



\section{3) Phase I: Results and Discussion}

\subsection{1) UV Transmission}

Table 1 shows the UV transmission in test water at a wavelength of $254 \mathrm{~nm}$ and $365 \mathrm{~nm}$ over the time period of the study. The variation in the UV transmission at both wavelengths shows that it is very important to know the minimum UV transmission of the water to calculate the required UV dose. Higher doses will be required as transmission is reduced. It is interesting to note that there was nine percent greater UV transmission at $365 \mathrm{~nm}$ than at $254 \mathrm{~nm}$, making this wavelength potentially more useful in low transmission waters. UV transmission is negatively affected by higher organic content and turbidity.

The average UV doses within the reaction vessels for the low pressure mercury lamp were 1.03 , $2.05,3.08$ and $4.10 \mathrm{~W} \cdot \mathrm{sec} / \mathrm{cm}^{2}$ while doses used for the medium pressure mercury lamp were 0.513 , $1.03,2.05$, and $3.08 \mathrm{~W} \cdot \mathrm{sec} / \mathrm{cm}^{2}$. These doses represent varying exposure periods at $500 \mu \mathrm{W} / \mathrm{cm}^{2}$.

\subsection{2) Veligers}

The dose response of zebra mussel veligers to the medium pressure lamp is shown in Figure 3. In excess of $90 \%$ mortality was achieved at $3.08 \mathrm{~W} \mathrm{sec} / \mathrm{cm}^{2}$. As can be seen, cooling did not alter the response of the veligers.

The batch tests with the low pressure mercury lamp did not result in significant mortalities relative to the controls. Even at doses as high as $4.1 \mathrm{~W} \mathrm{sec} / \mathrm{cm}^{2}$ mortalities of less than $50 \%$ were observed, (Figure 4).

These results are puzzling considering the lack of settlement observed during the previously mentioned study by Ontario Hydro. Measuring instantaneous mortality may not be a good indicator of the ability of the veligers to survive and to settle. The veligers may have undergone genetic damage which is not immediately reflected in mortality. Bacteria have been shown to continue metabolism after UV irradiation but they cannot form colonies on nutrient media. The UV doses used in this study are far in excess of the doses required to kill pathogenic 

TABLE 1 UV Transmissions $(1 \mathrm{~cm})$ in Batch Testing at $254 \mathrm{~nm}$ and $365 \mathrm{~nm}$

\begin{tabular}{|l|r|r|}
\hline \multirow{2}{*}{ DATE } & \multicolumn{2}{|c|}{ \% TRANSMISSION } \\
\cline { 2 - 3 } & $254 \mathrm{~nm}$ & $365 \mathrm{~nm}$ \\
\hline SEPT. 1 & 87.10 & 92.20 \\
\hline SEPT. 2 & 75.50 & 77.70 \\
\hline SEPT. 9 & 72.50 & 80.10 \\
\hline SEPT. 16 & 65.40 & 67.50 \\
\hline SEPT. 17 & 50.10 & 54.70 \\
\hline SEPT. 22 & 39.70 & 46.10 \\
\hline SEPT. 23 & 14.50 & 18.10 \\
\hline SEPT. 24 & 18.00 & 22.20 \\
\hline SEPT. 29 & 55.50 & 60.70 \\
\hline OCT. 1 & 20.20 & 23.60 \\
\hline OCT. 6 & 15.80 & 20.90 \\
\hline OCT. 8 & 12.30 & 12.30 \\
\hline
\end{tabular}





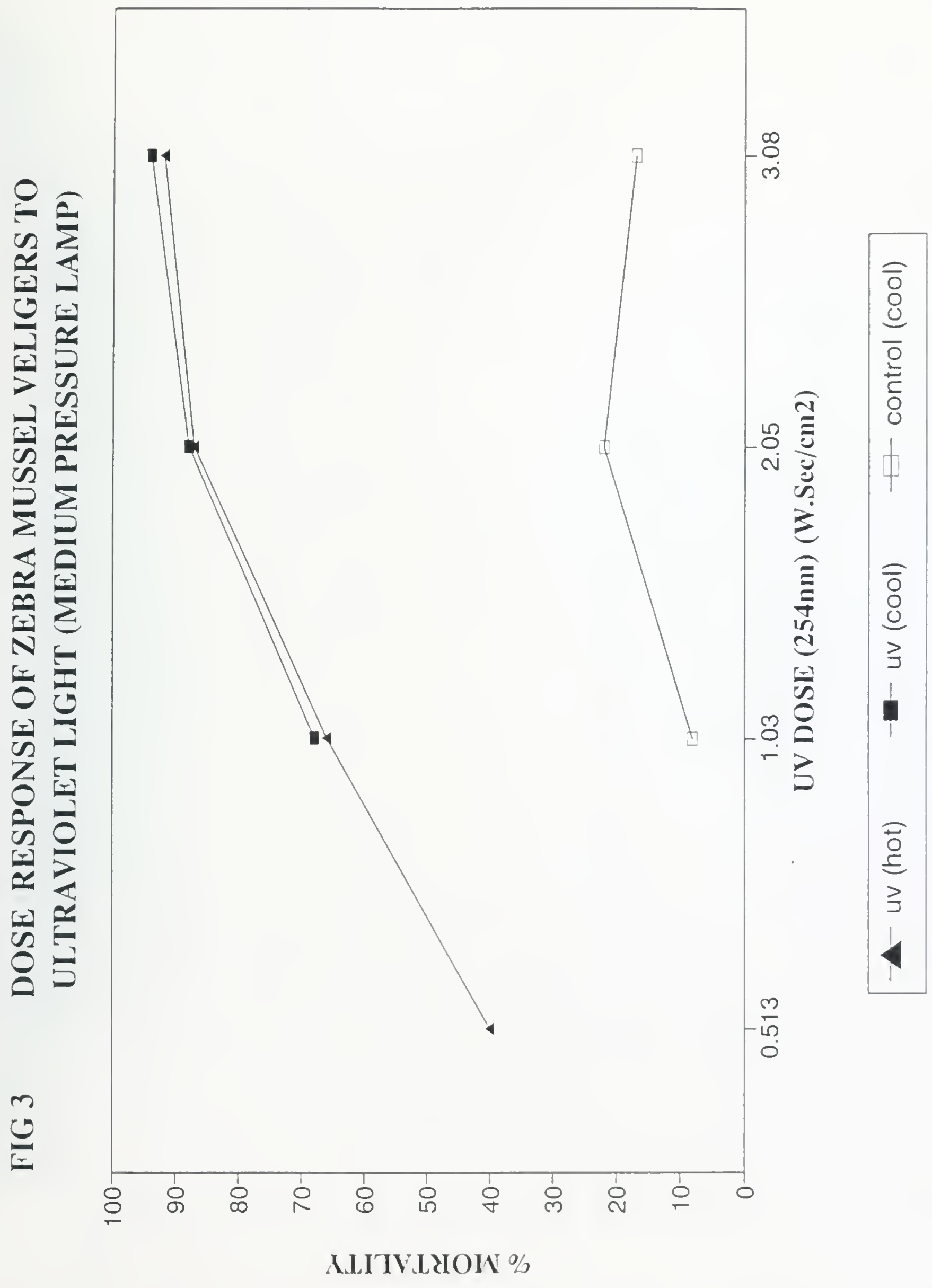


. 


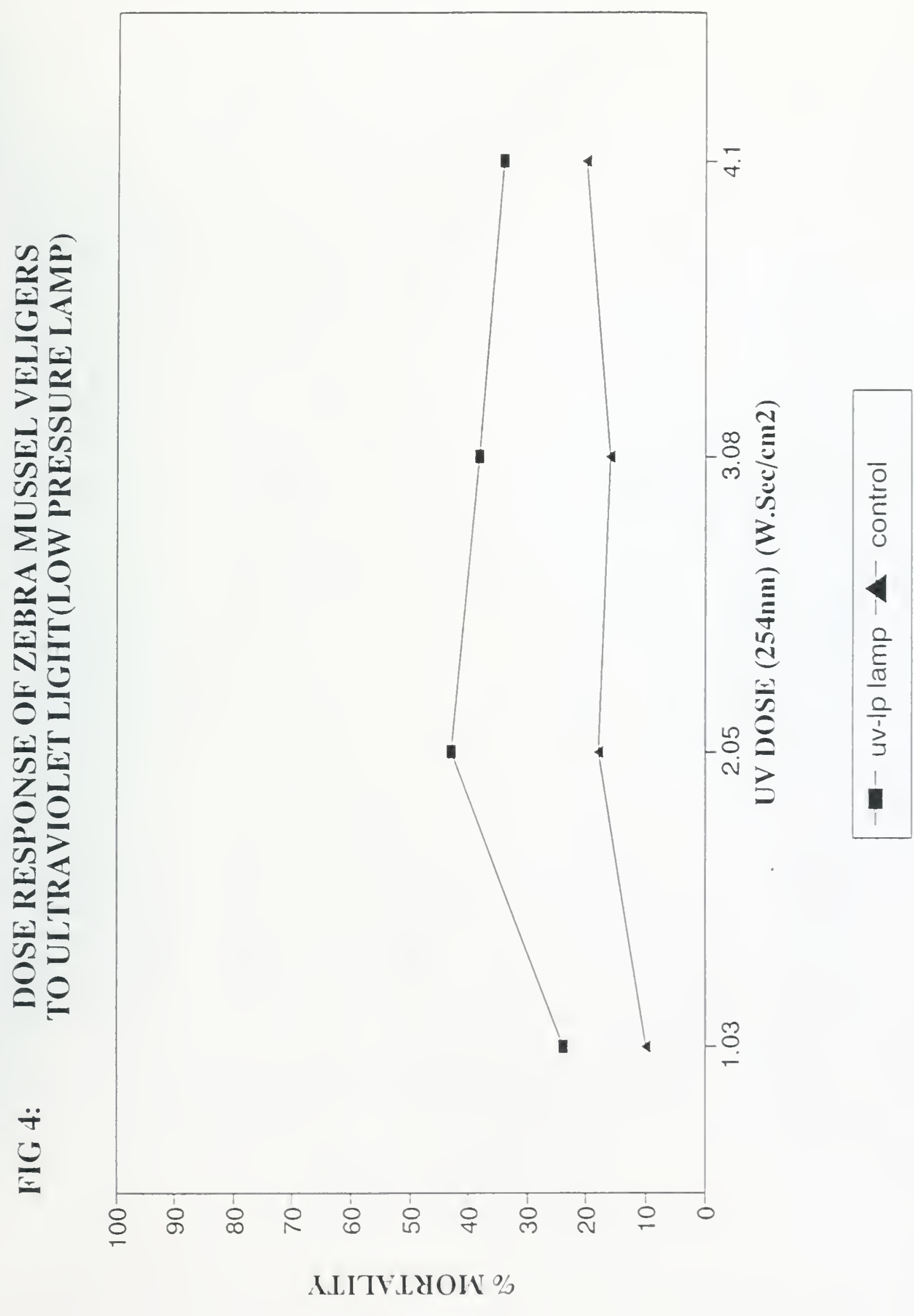





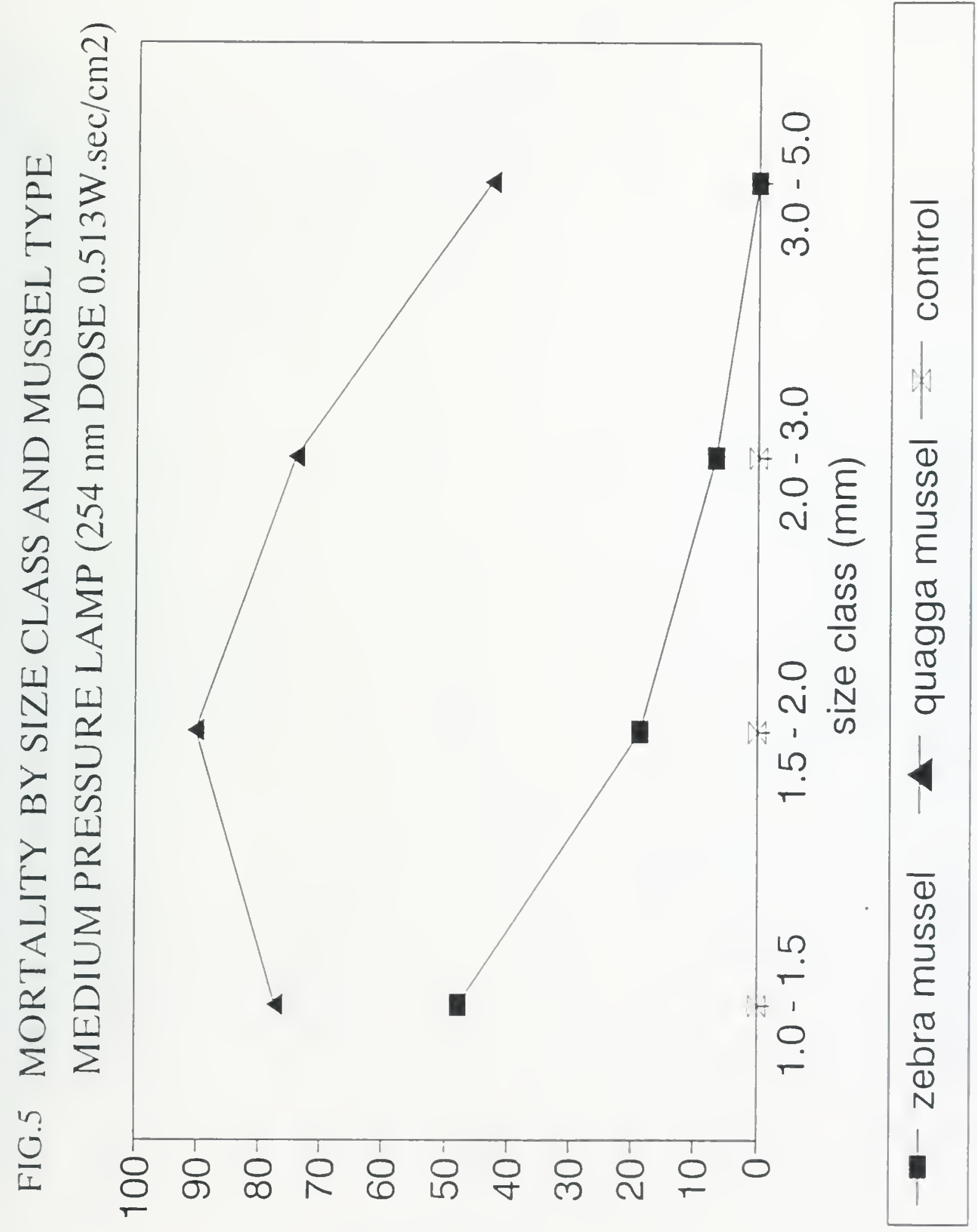

Kt!!enom \% 



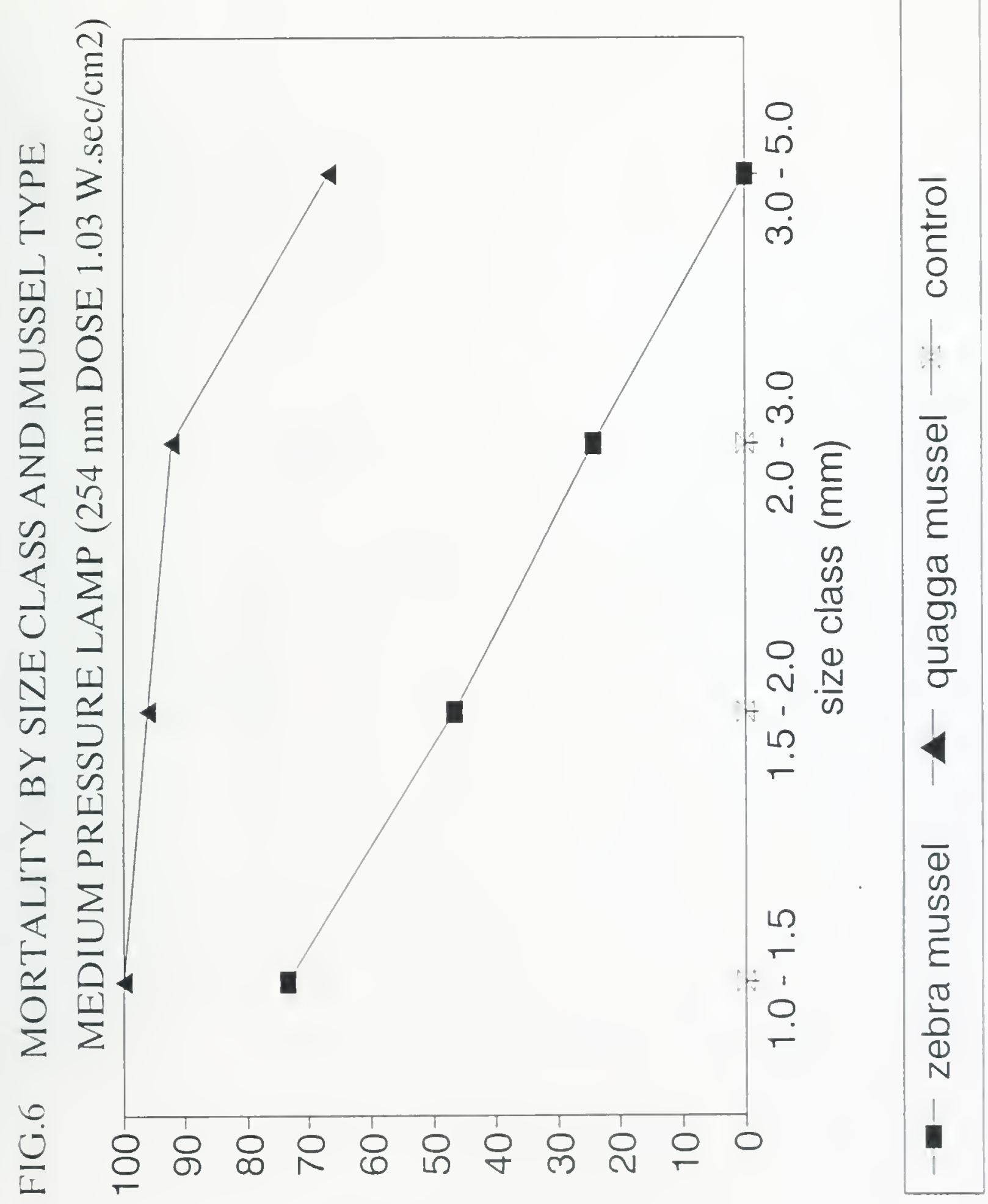

Kł!!enom \% 



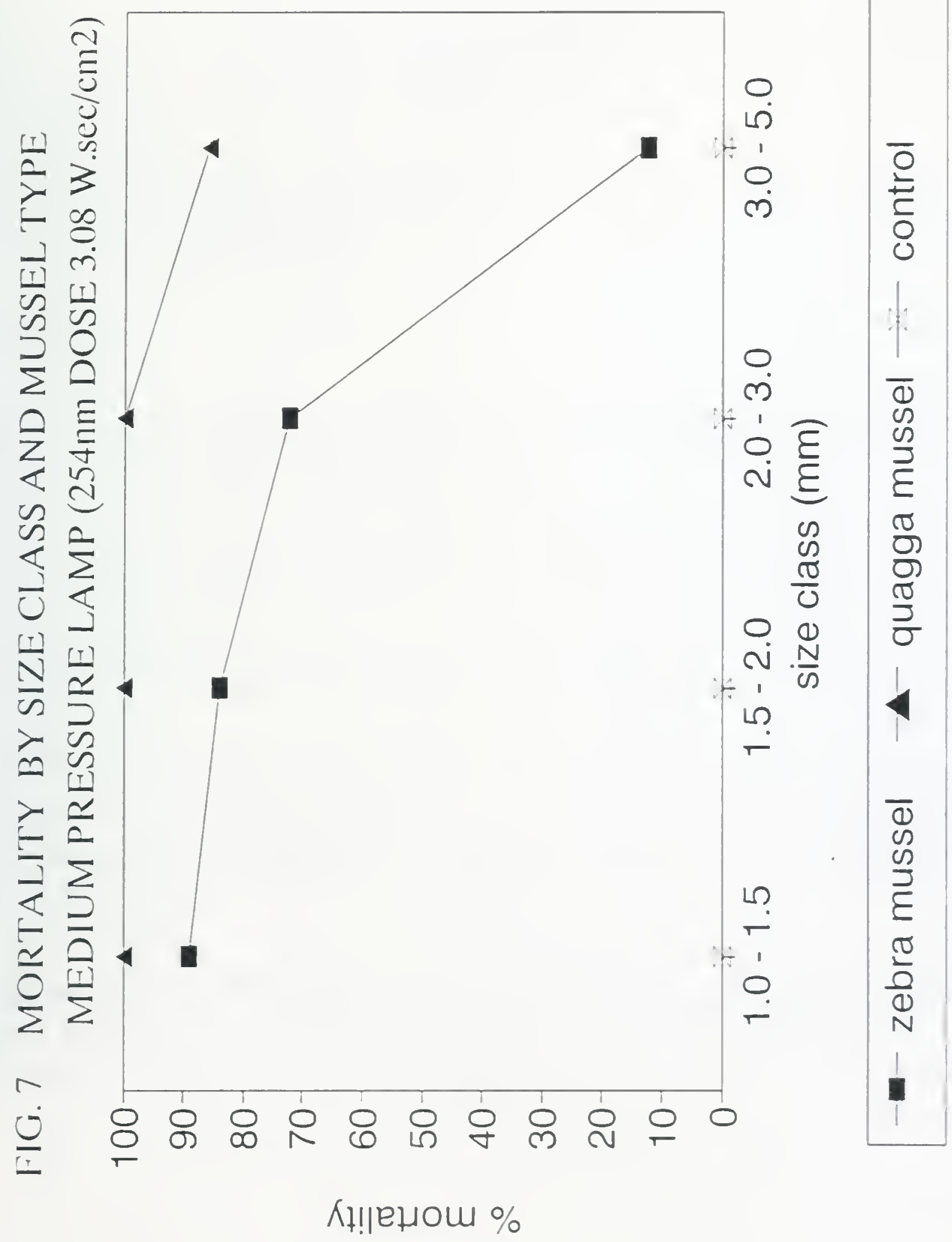



microorganisms in wastewater. The range of UV doses typically used for wastewater treatment applications are 0.03 to $0.140 \mathrm{~W} \mathrm{sec} / \mathrm{cm}^{2}$. The UV doses used in this study would kill all of the microorganisms which produce biological films on surfaces. As is typical of biological community development, the growth of biofilm on surfaces has been implicated in the settlement and growth of veligers. It may be that this phenomena also influenced the results of the previously mentioned Ontario Hydro study.

Throughout Phase I, handling and the action of the stirring bar never produced more than a $20 \%$ mortality rate in the unirradiated controls.

\subsection{3) Juveniles}

Tests on the juveniles were only done with the medium pressure mercury lamp due to the limited effect that the low pressure mercury lamp had on veligers.

Mortality rates in juvenile mussels were similar to those observed for veligers, for the same UV doses.

Mortality rates were related to both dose and mussel size (Figure 5-7).

Mussels were also broken down by species, allowing the effectiveness of the treatment for the zebra mussel and the newly identified quagga mussel to be compared. The juvenile quagga mussel appears to be substantially more susceptible to UV light from the medium pressure lamp than the zebra mussels. (Figure 5-7).

It should be noted that as the mussels grow they develop greater amounts of shell pigment. It has been observed throughout this research that zebra mussels usually show significantly greater levels of pigments than quagga mussels at these early life stages. 



\section{4) Phase I: Conclusions}

UV light from low or medium pressure mercury lamps will cause immediate post exposure mortality in both the veliger and juvenile stages of the zebra mussels but the UV doses are far in excess of those required to kill microorganisms.

Initial indications suggested that UV light was not a viable economical alternative to chemical oxidants due to the high dose requirement and therefore high capital and operational costs.

Immediate mortality of zebra mussels may not be the correct measure of UV light's ability to prevent the colonization of surfaces by the mussels, the primary concern of water users. Extensive research by ASI, Ontario Hydro and others indicates that the absence of a biofilm prevents the attachment of the zebra mussels. Since the mode of action of UV light at $254 \mathrm{~nm}$ is primarily the destruction of the genetic material of an organism, the damage may not show up for some time due to the slower metabolism and growth of the mussels compared to microorganisms.

Regardless of the mechanism, only flow through tests with settling chambers can be used to determine whether immediate mortality or the ability of the mussels to attach to surfaces, is the mechanism for control of mussels for this technology. These flow through tests will also provide a better guage of the economical viability of UV irradiation as a potential method for controlling the settlement or growth on downstream surfaces.

Ir addition, microbiological testing will determine the effect of UV light on the heterotrophic microorganisms which are an important component of the biofilm on surfaces. 



\section{0) PHASE II: FLOW THROUGH FIELD STUDIES \\ 4.1) Introduction}

Batch testing had appeared to indicate that although UV light could kill veliger and juvenile zebra mussels, it would require very high doses of UV light. The testing also provided evidence that instantaneous mortality may not be a good measure of the effectiveness of UV light for controlling downstream settlement. With this information in mind, four UV systems were designed to look at mussel attachment and mortality. A schematic of a typical system is shown in Figure 23.

In general, the system consisted of a water intake or pumping system which delivered mussel infested water to the UV contact chamber. Water passes through this chamber into a plexiglass settlement chamber, which houses PVC settlement plates, prior to discharge to a drain.

1. A single low pressure mercury lamp UV system $(254 \mathrm{~nm})$ was set up to repeat the study by Ontario Hydro. Similar flow rates were used which are in line with the UV doses used for killing microorganisms.

2. A multiple low pressure lamp UV system (254 nm) was used to simulate the apparently ineffective dosage levels indicated by the Phase I research. This was considered important since no latent mortalities were determined.

3. A UV unit with a single medium pressure lamp (200-400 nm) was employed to observe the effect of combining UVC and UVB radiation.

4. A single low pressure UV lamp (254 nm) was positioned in an open channel to observe the effect of continuous irradiation of surfaces on attachment by zebra mussels. 



\section{2) Methods}

All of the UV experiments were run simultaneously from June to November 1993, during the zebra mussel reproductive season.

A common pumping system drew water from the headworks at Ontario Hydro's Decew Hydro Electric facility in St. Catharines, Ontario. Veliger rich water was pumped into a common head tank which fed the four UV test systems and associated control tanks.

The single lamp pressurized UV system used one 36 watt low pressure mercury lamp producing 13.8 watts of UV light at a wavelength of $254 \mathrm{~nm}$ after 100 hours of use. The UV lamp was encased in a quartz sleeve to maintain the lamp at the proper operating temperature. The UV system is shown in Figure 8.

The multiple lamp pressurized UV system used eight 65 watt low pressure mercury lamps which each produce 26.7 watts of UV light at $254 \mathrm{~nm}$ after 100 hours use. The total UV output is 214 watts, after $10 \mathrm{hrs}$ use. The lamps are encased in quartz sleeves and the water is mixed by internal baffles to prevent short circuiting through the unit at low flow rates. The UV system is shown in Figure 8.

A second single lamp pressurized UV system used a 400 watt medium pressure mercury lamp (Philips) encased in a quartz sleeve. The spectrum of the lamp is shown in Figure 11. The UV system had an automatic shut-off switch if the flow of water stopped. The UV unit is shown in Figure 9.

The open channel UV system, shown in Figure 10, was set into a polycarbonate exposure chamber which measured approximately $66 \times 27 \times 22 \mathrm{~cm}$. The water depth was approximately $10 \mathrm{~cm}$. The lamp was more or less parallel to the flow of water along the length of the chamber. The low pressure mercury lamp uses 16 watts of power to produce 53 watts of UV light at a wavelength of $254 \mathrm{~nm}$ after 100 hours of use and is encased in a quartz sleeve. 


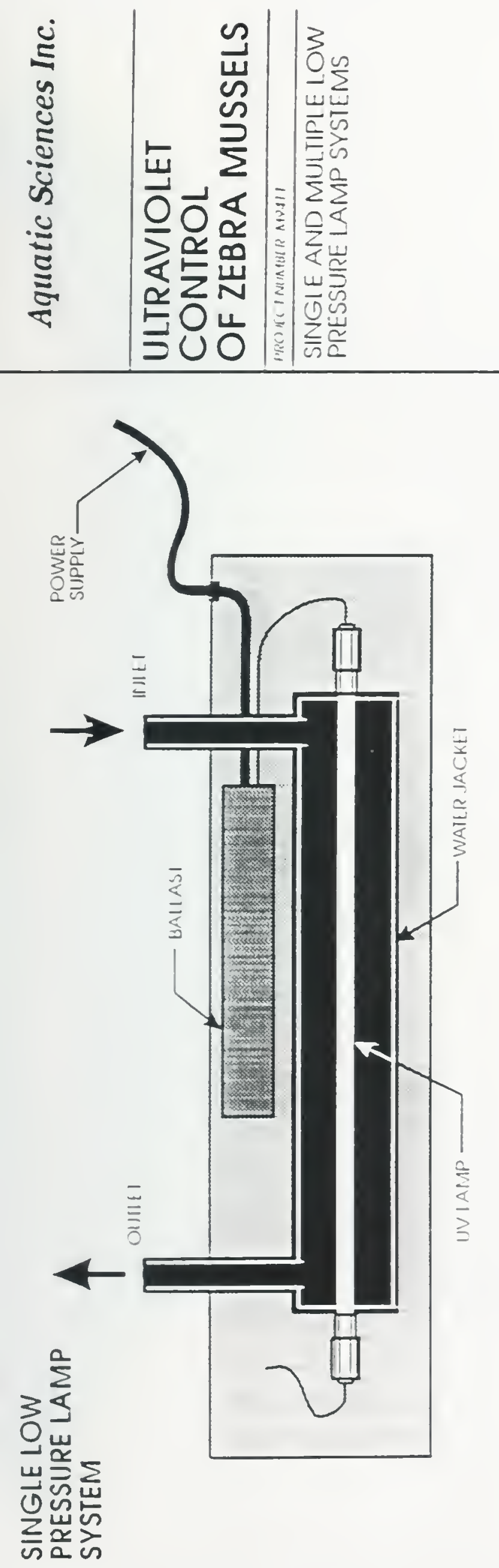

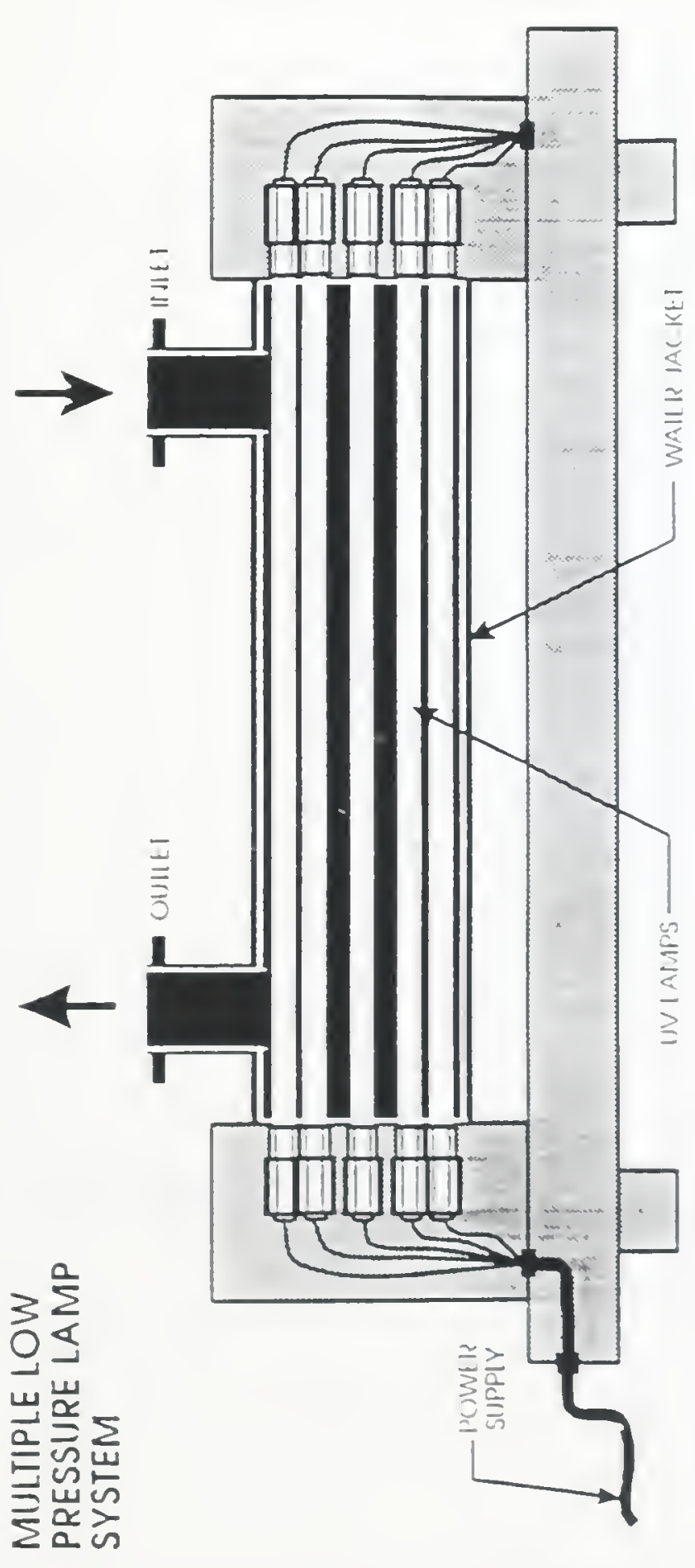




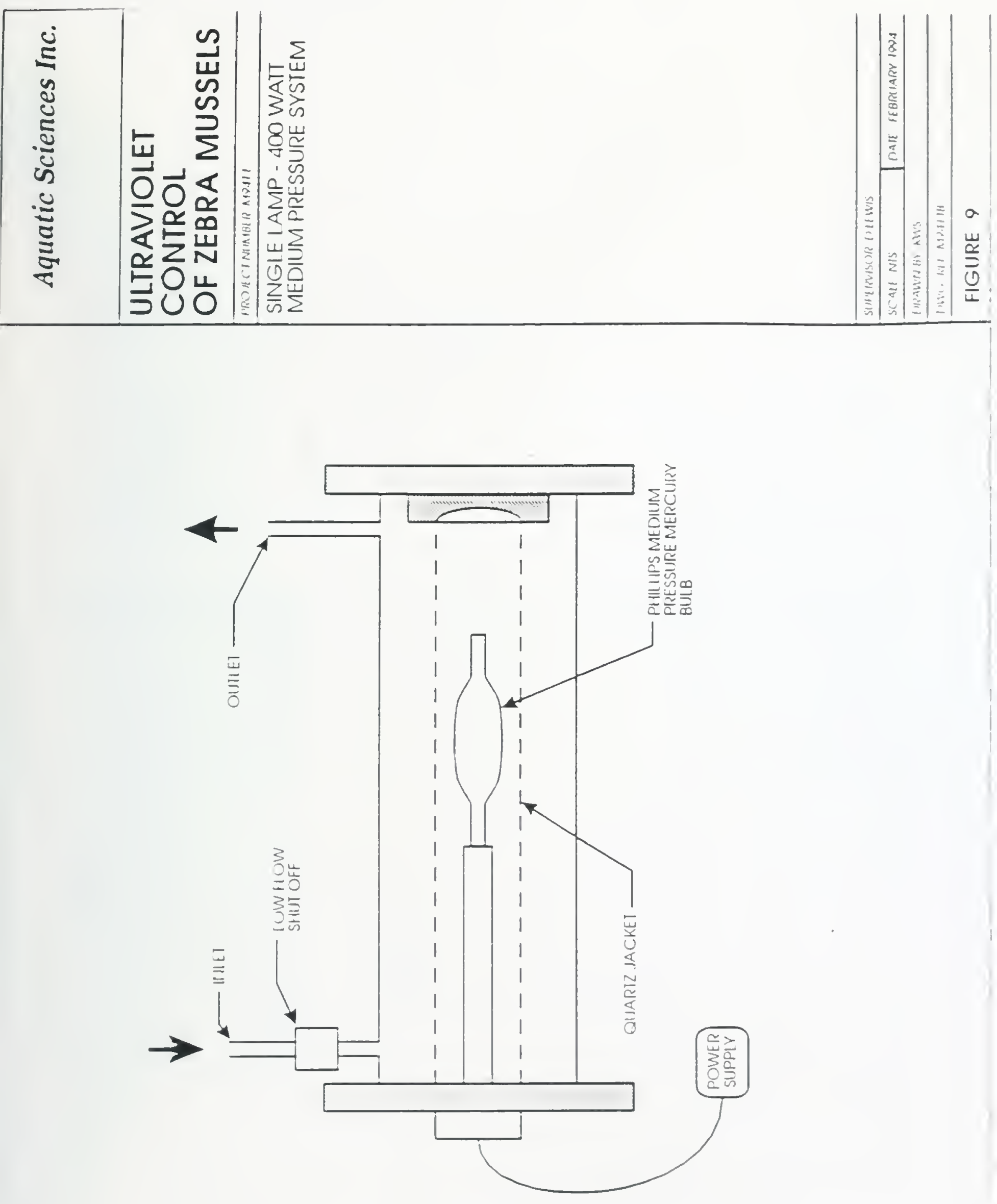



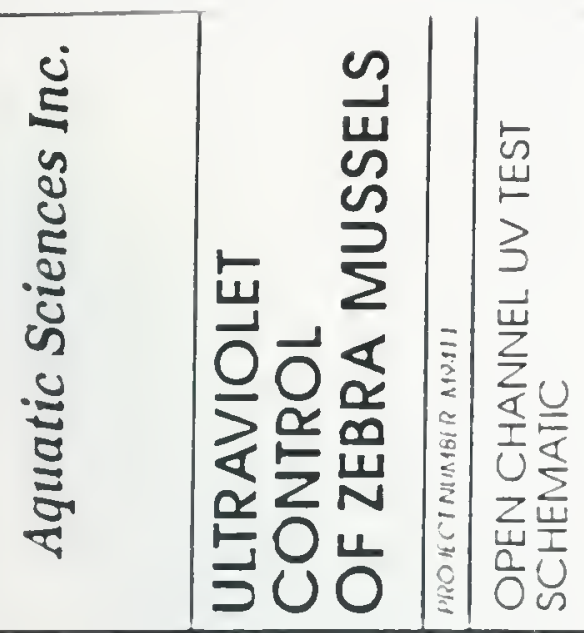




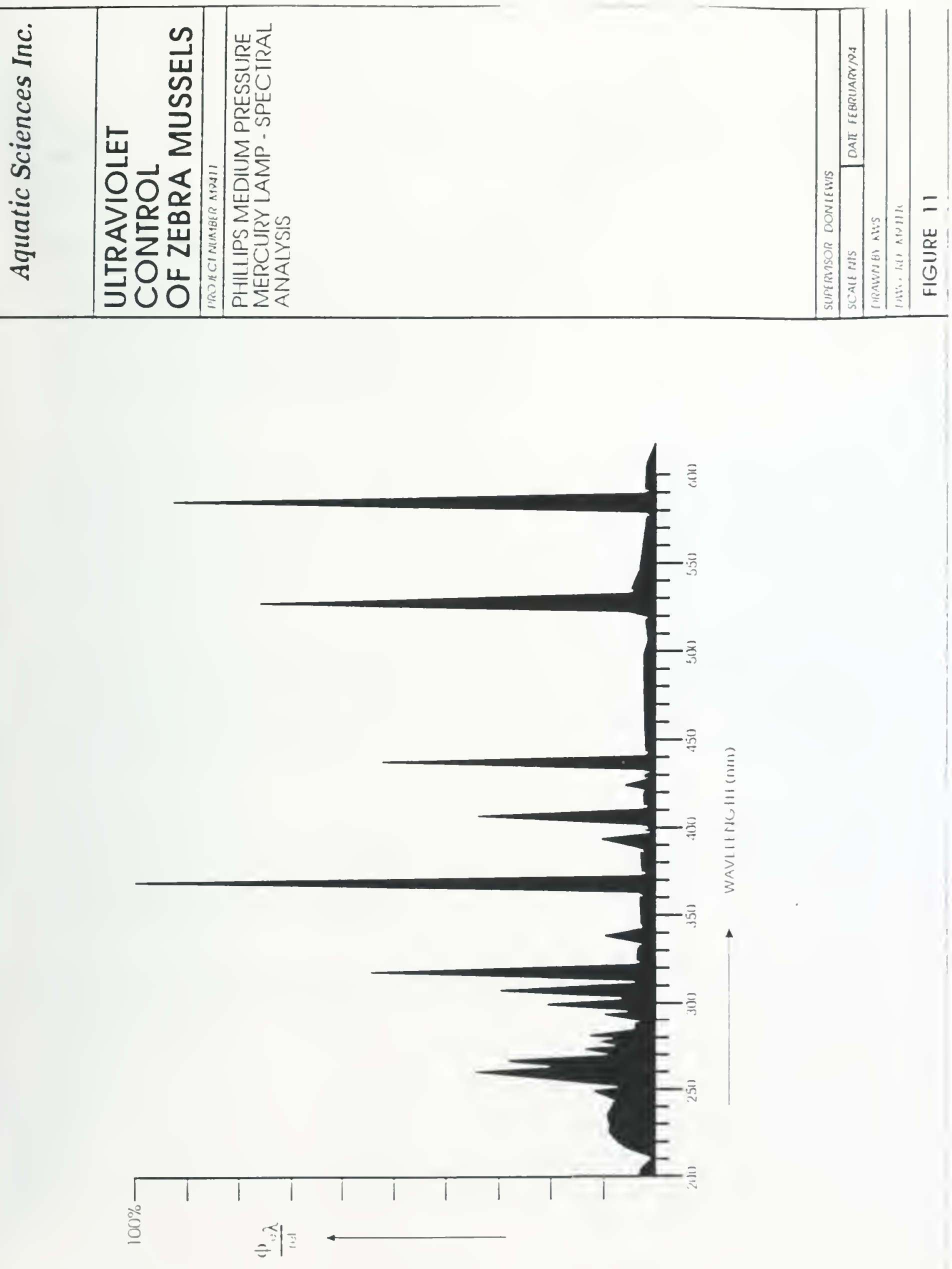

Each UV unit was installed in a separate exposure or test chamber. Each unit also had its own control chamber. Once the lamps were connected and operational, water flow to both the exposure and control chambers was initiated.

Initial water flows to each unit were as follows:

- multi-lamp, low pressure, $10 \mathrm{~L} / \mathrm{min}$

- $\quad$ single lamp, low pressure, 3-4 L/min

- $\quad$ single lamp, medium pressure, $6 \mathrm{~L} / \mathrm{min}$

- open channel, low pressure, 7-10 L/min

Flow rates remained at these levels throughout the study period with the exception of the single lamp, medium pressure unit. The flow rate through this unit was increased in September to 8 - 10 $\mathrm{L} / \mathrm{min}$ in an attempt to determine the upper limitations of this particular lamp type. Flow was increased again in October to $10-15 \mathrm{~L} / \mathrm{min}$.

Filtered water samples (20 litre) were taken at the effluent of each UV settling chamber and control tank three times per week and analyzed for the presence, age, density and mortality of free swimming veligers and post veligers. Culture plates, installed in each tank prior to testing, were scraped and analyzed for settled mussels.

The effectiveness of the four UV units for prevention of zebra mussel settlement was also measured after the termination of the study. Scrapings taken from the tank walls were analyzed for the presence of settled zebra mussels.

During the test period, significantly fewer larval mussels were detected at the effluent end of the UV systems when compared to controls.

At the end of the study period, the control and test tanks for the single lamp medium pressure unit, as well as the multiple lamp low pressure unit were cleaned out and the lamps were restarted. A five day sediment analysis study was performed for the purpose of determining whether the mussel larvae were being removed from the water column, and settling in the downstream chamber or 

were being destroyed by the UV light, a phenomena reported by Chalker-Scott et al., (1994). Sediment from a known area was collected from the bottom of each settlement chamber following five days of continuous operation and analyzed for the pressure of zebra mussel larvae.

As previously documented, Aquatic Sciences Inc. has observed during numerous research project that the development of a biofilm appears to be important prior to zebra mussel settlement on newly submerged surfaces. In order to provide more information about the mechanism by which UV may control zebra mussel settlement, a study of bacterial counts post UV treatment was made, as these bacteria are an integral part of biofilm make up.

Appendix I contains methodologies used to sample and analyze for reductions in bacterial counts, post UV treatment.

\section{3) Phase II Flow Through Field Studies: Results and Discussion}

\subsection{1) UV Transmission}

The results of the UV transmission for flow through studies at wavelengths of $254 \mathrm{~nm}$ and $365 \mathrm{~nm}$ are shown in Table 2.

The average UV transmission at a wavelength of $254 \mathrm{~nm}$ and $365 \mathrm{~nm}$ was $95 \%$ and $98 \%$ respectively which are in the same range as drinking water, whereas the UV transmissions in Phase I were much lower. These types of fluctuations are due to incoming water quality. Transmission varies according to turbidity and organic content which may change depending on weather conditions.

Higher UV transmissions allow the UV light to penetrate the water easily, thereby reducing the size of that unit and therefore capital cost of a full scale UV system.

Since the UV transmission was accounted for in Phase I and Phase II to calculate the UV dose, it cannot be used to account for the differences in the mortality of the post veligers between Phase I and Phase II testing. The UV unit with the single low pressure mercury lamp was producing a 

TABLE 2 UV Transmissions $(1 \mathrm{~cm})$ During Flow Through Tests at $254 \mathrm{~nm}$ and $365 \mathrm{~nm}$

\begin{tabular}{|c|c|c|}
\hline \multirow[t]{2}{*}{ DATE } & \multicolumn{2}{|c|}{ \% TRANSAAISSION } \\
\hline & $254 \mathrm{~nm}$ & $365 \mathrm{~nm}$ \\
\hline JULY 14 & 85.50 & 91.01 \\
\hline JULY 18 & 88.20 & 94.97 \\
\hline JULY 19 & 96.38 & 99.30 \\
\hline JULY 21 & 93.80 & 96.94 \\
\hline JULY 23 & 95.06 & 98.70 \\
\hline JULY 26 & 91.00 & 97.14 \\
\hline JULY 28 & 94.54 & 97.33 \\
\hline JULY 30 & 96.32 & 98.75 \\
\hline AUG. 3 & 94.26 & 97.34 \\
\hline AUG. 6 & 95.97 & 98.60 \\
\hline AUG. 9 & 94.81 & 98.30 \\
\hline AUG. 11 & 94.28 & 96.84 \\
\hline AUG. 13 & 95.06 & 98.00 \\
\hline AUG. 16 & 95.82 & 98.76 \\
\hline AUG. 18 & 95.17 & 97.80 \\
\hline AUG. 20 & 95.86 & 98.56 \\
\hline AUG. 23 & 95.62 & 98.40 \\
\hline AUG. 25 & 96.40 & - \\
\hline AUG. 27 & 96.50 & 98.70 \\
\hline AUG. 30 & 97.70 & 98.20 \\
\hline SEPT. 1 & 97.60 & 99.40 \\
\hline SEPT. 8 & 97.10 & 99.00 \\
\hline SEPT. 10 & 96.10 & 98.60 \\
\hline SEPT. 15 & 94.60 & 97.40 \\
\hline SEPT. 17 & 94.80 & 98.00 \\
\hline SEPT. 20 & 96.20 & 98.30 \\
\hline SEPT. 22 & 96.10 & 98.60 \\
\hline SEPT. 24 & 95.50 & 98.30 \\
\hline SEPT. 29 & 96.50 & 98.90 \\
\hline OCT. 1 & 88.90 & 92.10 \\
\hline OCT. 4 & 94.00 & 96.90 \\
\hline OCT. 6 & 92.80 & 95.00 \\
\hline OCT. 8 & 93.70 & 98.10 \\
\hline OCT. 15 & 96.10 & 98.30 \\
\hline OCT. 29 & 95.00 & 98.00 \\
\hline NOV. 17 & 94.60 & 97.90 \\
\hline AVERAGE & 94.66 & 97.61 \\
\hline
\end{tabular}



UV dose which was less than one tenth of what was used in the batch tests in Phase I, however mortalities were much higher.

\subsection{2) Sample Analysis}

The results of water sample analysis for post veliger densities and relative viable proportions are graphically illustrated in Figures 12 through Figure 16-2. Samples were collected from the head tank upstream of the UV systems, the bioboxes downstream from the UV systems and from the control bioboxes.

The results of juvenile settlement densities for each UV unit and control tank during the study are shown in Figures 17 to 20.

\subsubsection{1) Single Lamp - Low Pressure Unit (254 nm)}

Total post veliger densities and relative viable proportions for the single low pressure mercury pressurized UV unit are shown in Figures 13-1 and 13-2. The relatively low densities observed downstream of the UV unit make it difficult to make meaningful interpretation of this data other than the notable reduction in total numbers in the test tank.

Post veliger densities at the settling chamber effluent from the UV unit were generally observed to be $<1,000 / \mathrm{m}^{3}$, although a peak post veliger density of $3,500 / \mathrm{m}^{3}$ was observed on July 16 (Figure 13-2). This is apparently because the UV unit was not operational on July 16 and July 19 although flow had not been terminated.

Post veliger densities at the control tank effluent were much higher, frequently exceeding $10,000 / \mathrm{m}^{3}$ and peaking at $49,000 / \mathrm{m}^{3}$ (Figure 13-1).

The relative proportion of viable post veligers observed after the control tanks was greater than those observed from the test tank (Figure 13-1 and 13-2). The percentage of viable post veligers 

FIGURE 12: TOTAL POST VELIGER DENSITY AND RELATIVE VIABLE PROPORTION IN TIE HEAD TANK WATER FLOW - I993

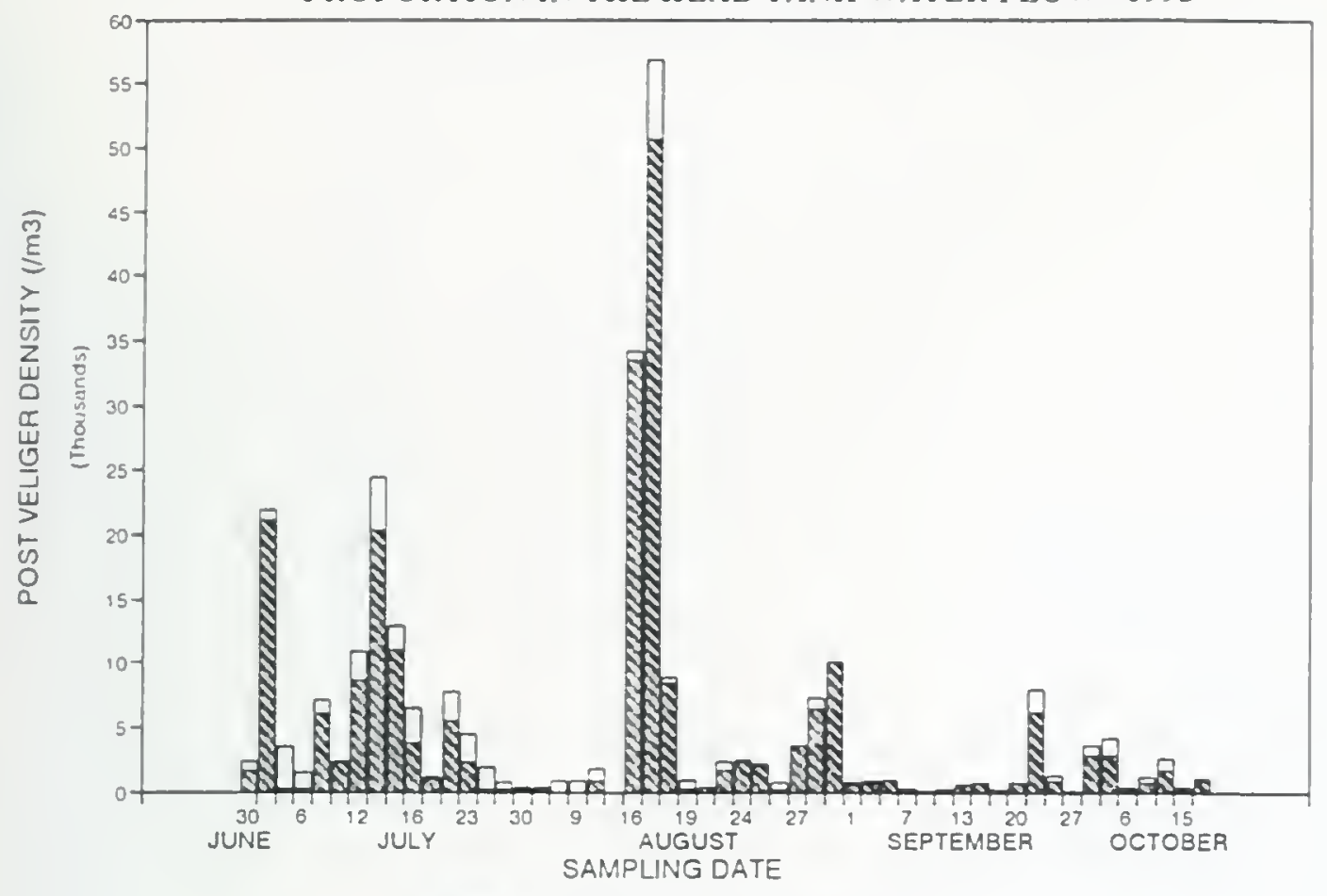

III viable larvae total larvae 

FIGURE 13.1: TOTAL POST V'ELIGER DENSITY AND RELATIVE V'IABLE PROPORTION IN THE SINGLE LAMP - LOW PRESSURE SYSTEM CONTROL BIOBOX

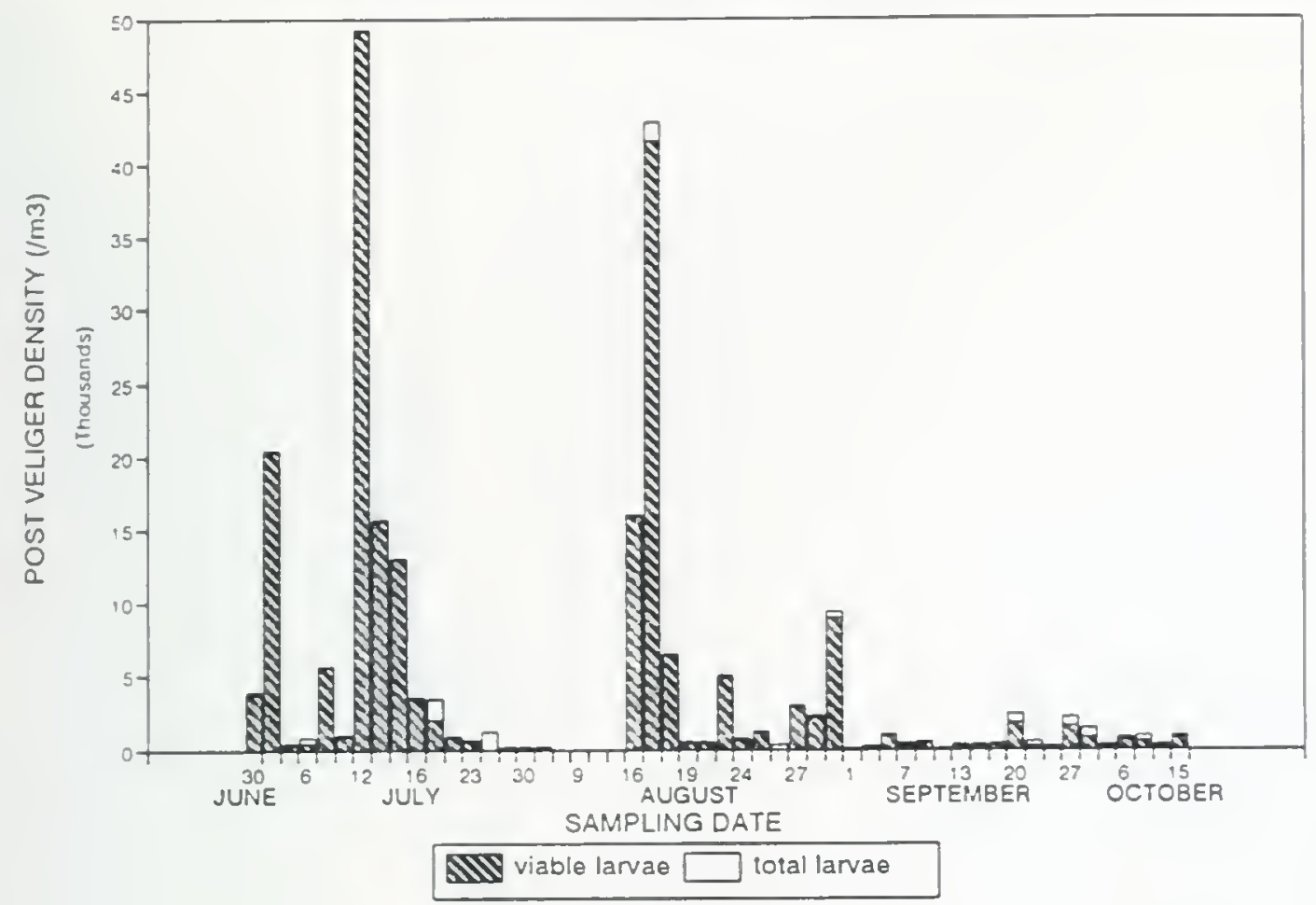

FIGURE 13-2: TOTAL POST VELIGER DENSITY AND RELATIVE VIABLE PROPORTION IN TIIE SINGLE LAMP - LOW PRESSURE SYSTEM TEST BIOBOX

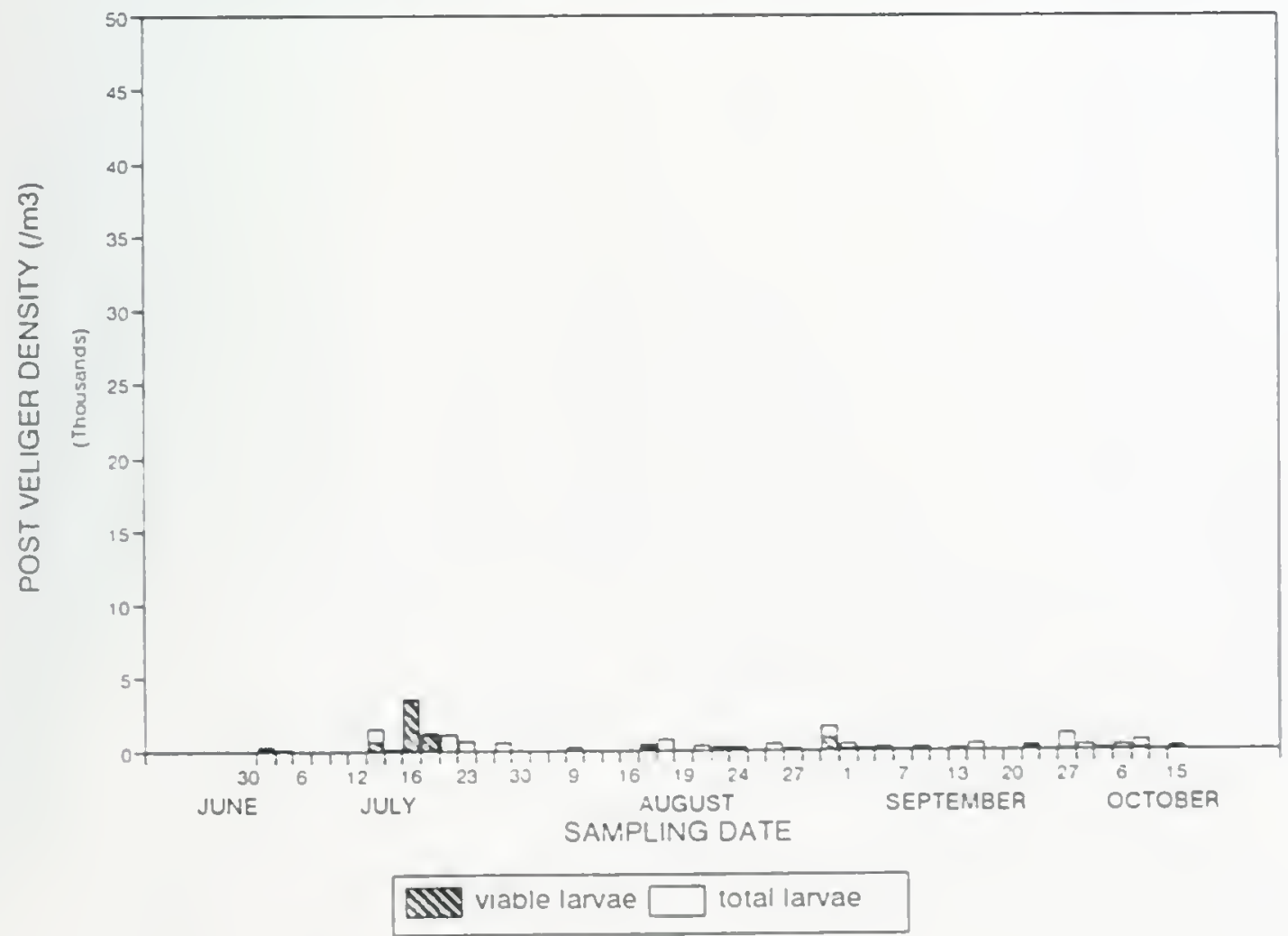



FIGURE 14-1: TOTAL POST V'ELIGER DENSITY AND RELATIVE VIABLE PROPORTION IN THE MULTIPLE LAMP - LOW PRESSURE SYSTEM CONTROL BIOBOX

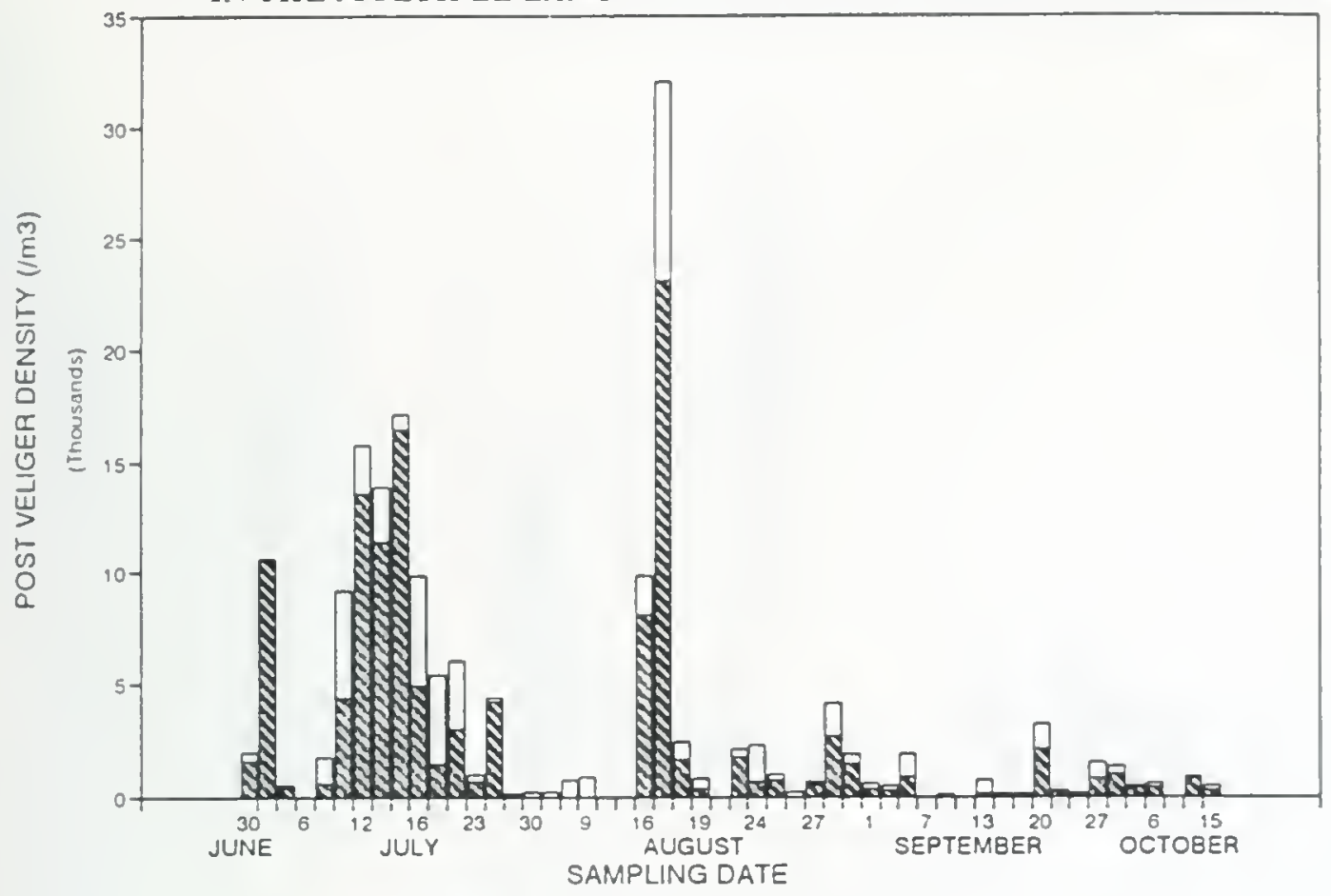

AIN viable larvae $\square$ total larvae

FIGURE 14-2: TOTAL POST VELIGER DENSITY AND RELATIVE VIABLE PROPORTION IN THE MIULTIPLE LAMP - LOW PRESSURE SYSTEM TEST BIOBOX

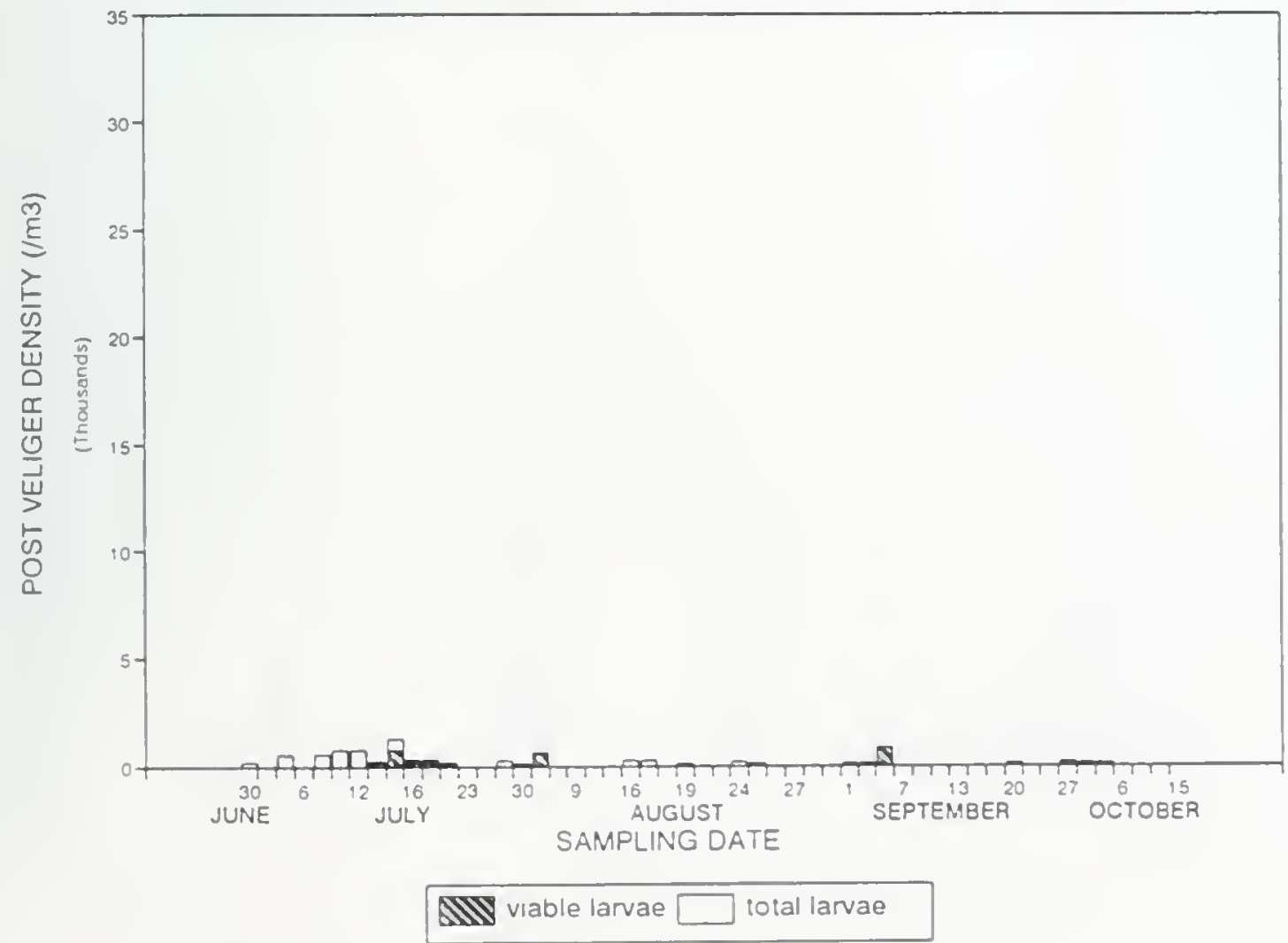



FIGURE 15-1: TOTAL POST VELIGER DENSITY AND RELATIVE VIABLE PROPORTION IN TIIE OPEN CIYANNEL - LOW PRESSURE SYSTEM CONTROL BIOBOX

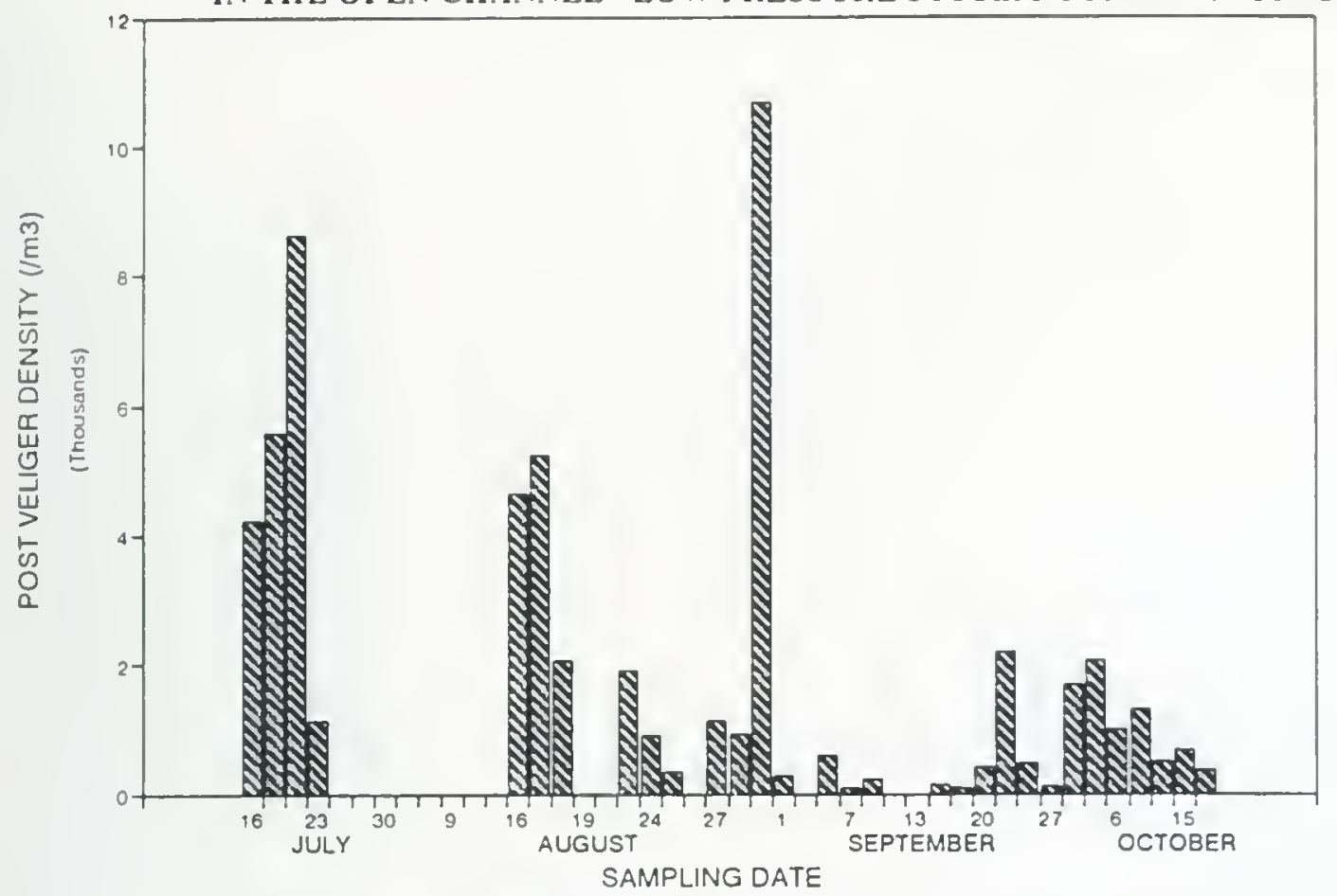

MIN viable larvae $\square$ total larvae

FIGURE 15.2: TOTAL POST VELIGER DENSITY AND RELATIVE VIABLE PROPORTION IN THE OPEN CHANNEL - LOWV PRESSURE SYSTEM TEST BIOBOX

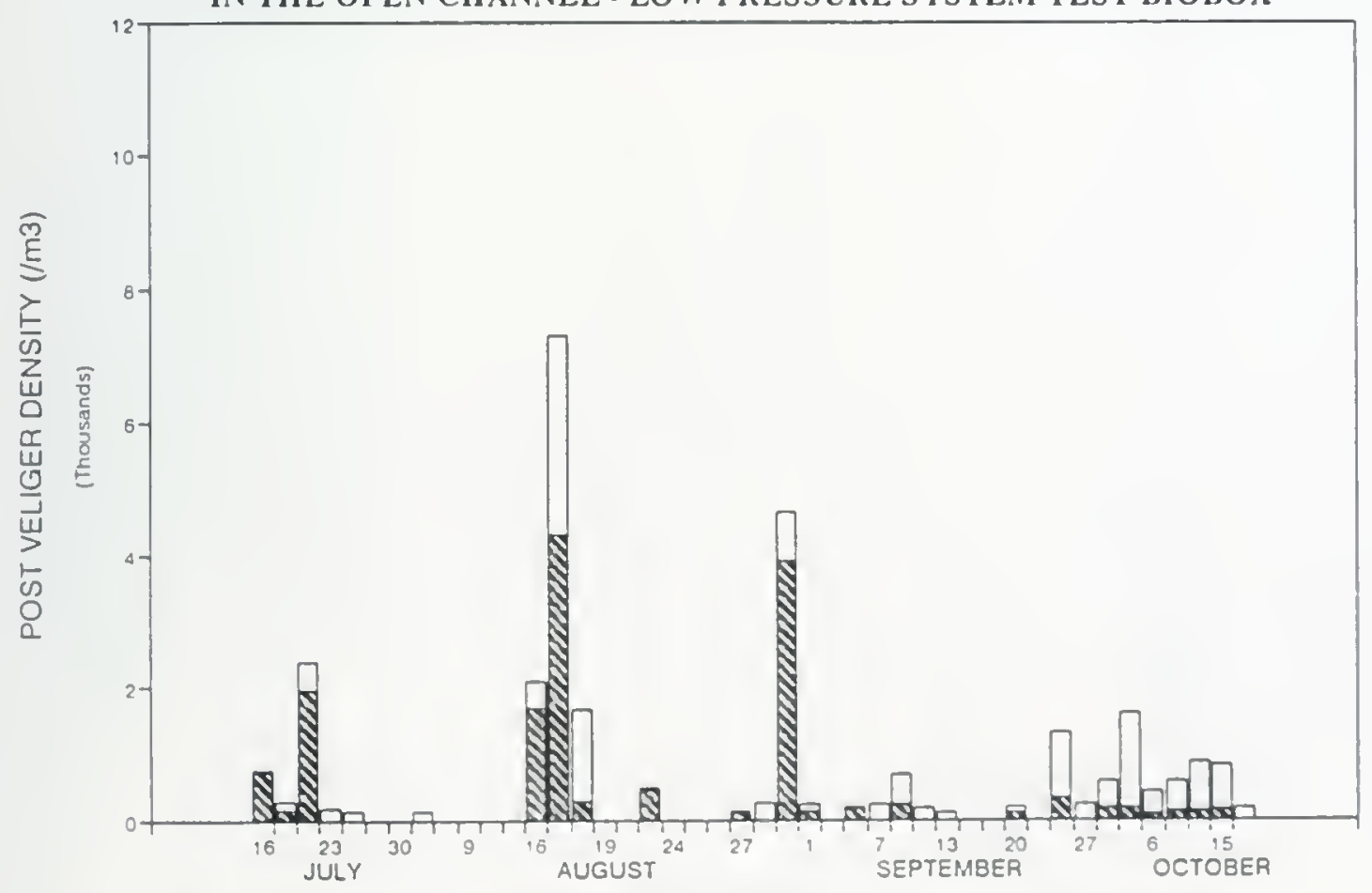

SAMPLING DATE

AII viable larvae $\square$ total larvae 

FIGURE 16-1: TOTAL POST VELIGER DENSITY AND RELATIVE VIABLE PROPORTION IN TIIE SINGLE LAMP - MEDIUM PRESSURE SYSTEM CONTROL BIOBOX

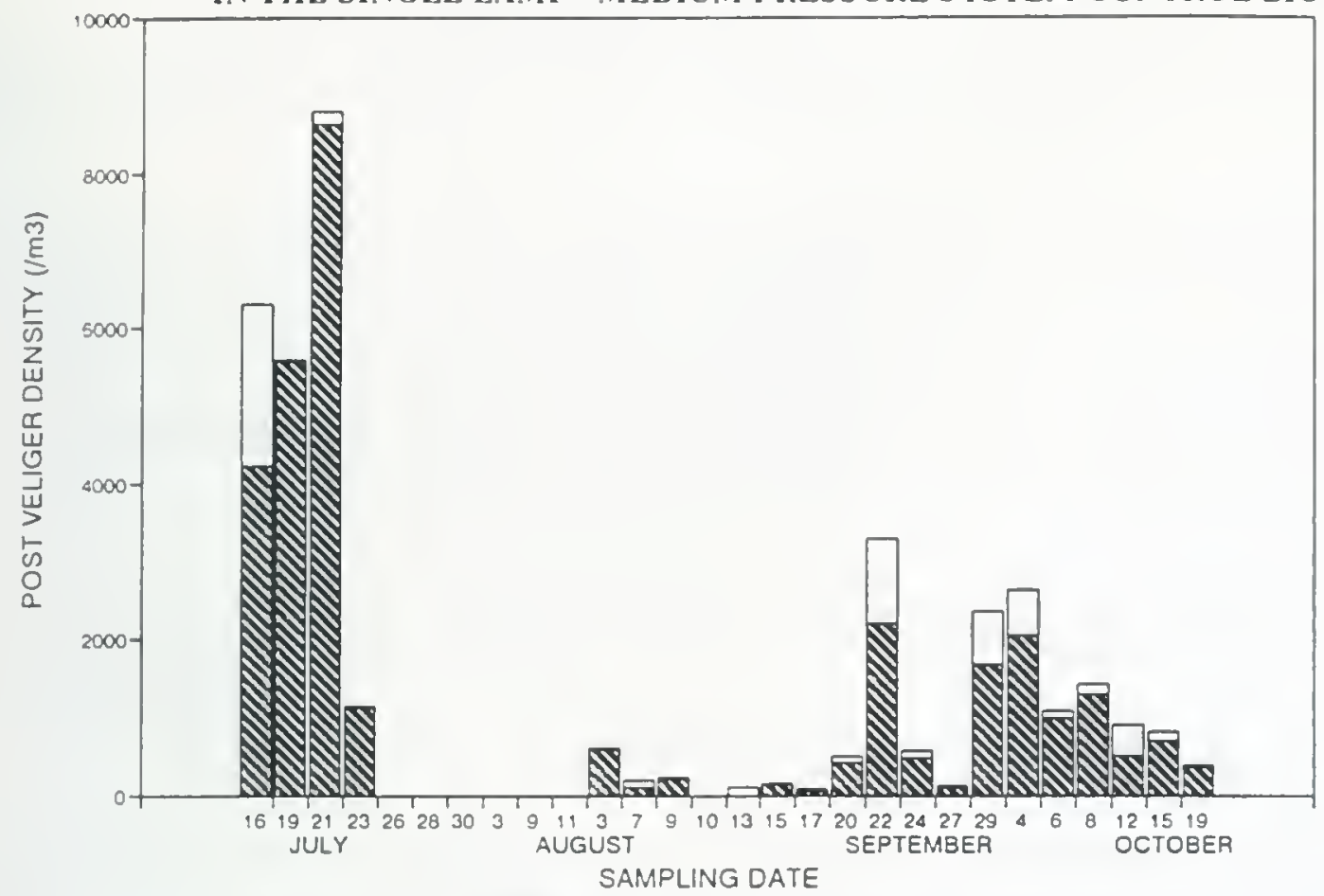

AII viable larvae $\square$ total larvae

FIGURE 16-2: TOTAL POST VELIGER DENSITY AND RELATIVE VIABLE PROPORTION IN THE SINGLE LAMP- MEDIUM PRESSURE SYSTEM TEST BIOBOX

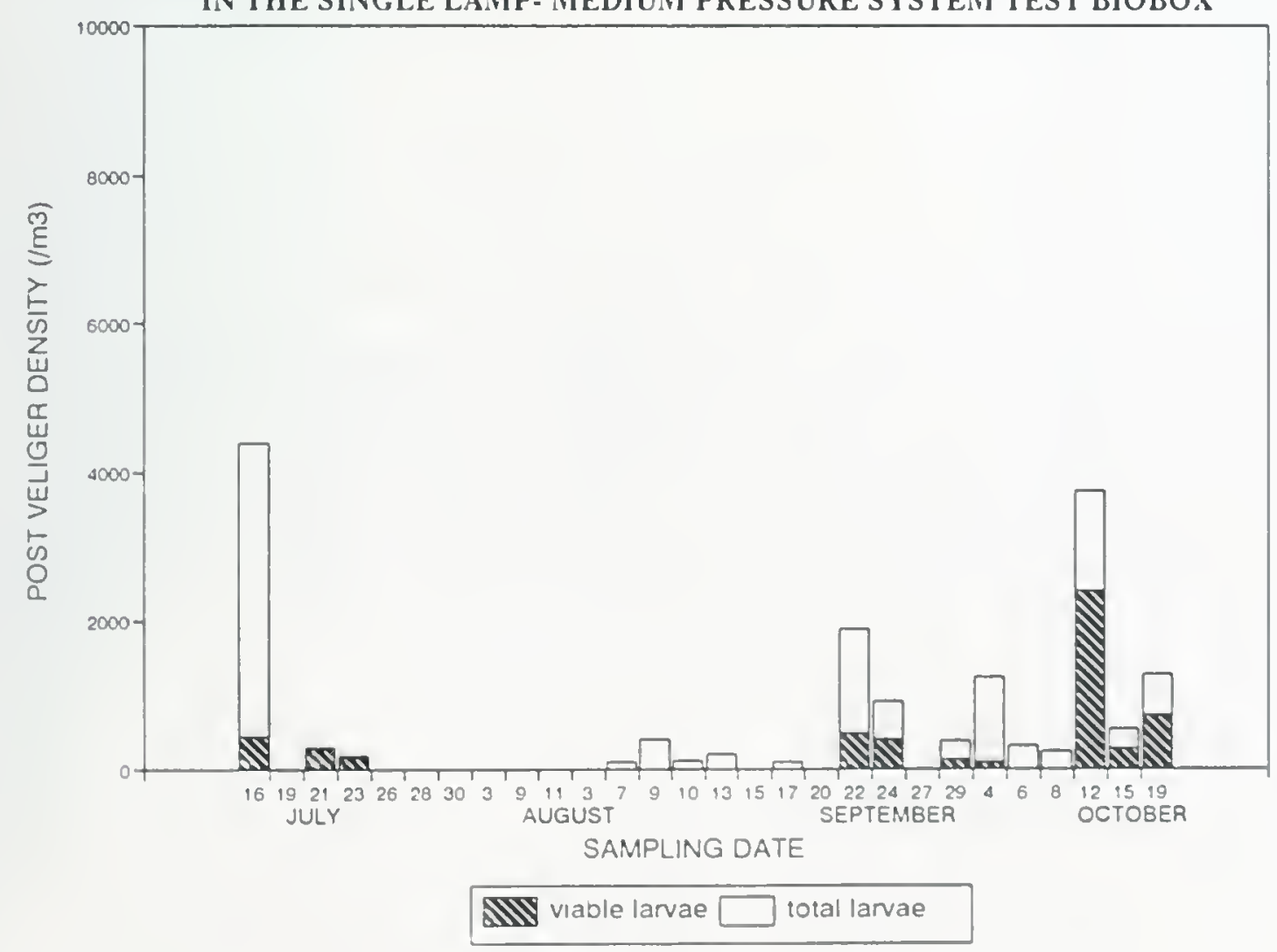



was usually $<50 \%$ in the samples taken from the test system while control system samples indicated that with few exception (July 24), $80-100 \%$ of the post veligers were viable.

While settlement on culture plates downstream of UV test systems was greatly reduced relative to controls, settled juveniles were observed on the culture plates on July 26 and August 9 (see Figure 17). Mortality rates were observed to be 0 and $100 \%$ respectively. The July sampling date closely followed the period during which the UV lamp was "off line". Post veliger larvae may have settled on the plates at this time after passing through the UV unit without being exposed to the UV light.

More frequent settling, as well as greatly increased densities of settled juveniles were observed in the control tank (Figure 17).

Based on a flow rate of $10 \mathrm{~L} / \mathrm{min}$, the post exposure contact time in the settling tanks was estimated to be 2.7 minutes, while the exposure time in the UV system was only a few seconds.

These results are similar to the Ontario Hydro study which also showed an inhibition of post exposure settlement.

The effect of the UV light at a wavelength of $254 \mathrm{~nm}$ in the flow through UV system appears to contrast the results with the batch tests. The UV doses in the batch tests ranged from 1 to 4 W $\mathrm{sec} / \mathrm{cm}^{2}$ and were far in excess of those in the flow-through unit where doses were approximately $0.08 \mathrm{~W} \cdot \mathrm{sec} / \mathrm{cm}^{2}$. Dose has two components, intensity and time. Time was greater in the batch tests resulting in higher overall doses, however, the intensity was far greater in flow-through tests. In the batch test the UV intensity was $500 \mu \mathrm{W} / \mathrm{cm}^{2}$, whereas in the flow through tests the average UV intensity in the chamber was $17,750 \mu \mathrm{W} / \mathrm{cm}^{2}$ or 35.5 times as great. It may be that a threshold intensity for efficacy against mussel larvae exists which was above that present in the low pressure batch tests. 




\subsubsection{2) Multiple Lamp - Low Pressure System (254 nm)}

Total post veliger densities and the relative viable proportion in the multiple lamp - low pressure system control and test effluents are graphically illustrated in Figures 14-1 and 14-2.

Post veliger densities observed in the test settling chamber effluent were consistently below $1,000 / \mathrm{m}^{3}$ with the exception of July 14 when post veliger density peaked at $1,300 / \mathrm{m}^{3}$.

In contrast, the post veliger densities were almost always above $1,000 / \mathrm{m}^{3}$ and during July and August, peaks above $10,000 / \mathrm{m}^{3}$ were observed in the control tank effluent. Post veliger densities peaked in the control tank at $32,000 / \mathrm{m}^{3}$ (Figure 14-1).

The relative proportion of viable post veligers to total veligers observed in the test system was difficult to determine in a meaningful way due to the extremely low densities observed in the settling chamber downstream of the UV unit (Figure 14-2).

No settled juveniles were detected in any of the culture plate scraping samples taken from the settling chamber downstream of this UV unit during the study period, however, a small number were detected on the outlet wall of the settling tank (Figure 18).

Culture plate scrapings from the control tank, however, showed that settled juveniles were detected in densities of approximately $1,000 / \mathrm{m}^{2}$ to $2,500 / \mathrm{m}^{2}$.

Based on a flow rate of $10 \mathrm{~L} / \mathrm{min}$, the post exposure contact time in the settling chamber for this unit was estimated to be 2.7 minutes, while exposure time in the contact chamber would be measured in seconds.

The increase in the number of UV lamps produced a UV dose at 10 litres per minute of $2.6 \mathrm{~W} \cdot \mathrm{sec} / \mathrm{cm}^{2}$ which was in the same range as the previous season's batch tests. The average UV intensity in this flow through UV system was $22,300 \mu \mathrm{W} / \mathrm{cm}^{2}$ which was $45 x$ that used for batch tests with the low pressure lamps. 


Again, while the relatively short contact time reduces the overall calculated exposure dose, the large increase in intensity may have exceeded some threshold level whereby mussel larvae are damaged or killed in a very short period.

\subsubsection{3) Open Channel - Low Pressure System (254 nm)}

Total post veliger densities and relative viable proportions for the open channel - low pressure system and its control are shown in Figures 15-1 and 15-2.

Post veliger densities in the settling chamber effluent, which contained the open channel UV system, were observed to be less than $4,000 / \mathrm{m}^{3}$ during July and August and less than $2,000 / \mathrm{m}^{3}$ during September and October. The peak post veliger density was $7,300 / \mathrm{m}^{3}$, observed on July 17 (Figure 15-2).

The control tank effluent sampling showed that mussel densities frequently exceeded $6,000 / \mathrm{m}^{3}$ in July and August and ranged from less than $1,000 / \mathrm{m}^{3}$ up to $2,000-3,000 / \mathrm{m}^{3}$ in September and October (Figure 15-1). The post veliger density peaked at $16,300 / \mathrm{m}^{3}$ on August 17 .

The relative proportion of viable post veligers in effluent samples was generally higher in the control tank. In October, the number of viable post veligers observed in the sample decreased dramatically, $(<20 \%)$, in the tank with the UV lamp while remaining high, $>80 \%$, in the control (Figure 15-1 and 15-2).

Juvenile mussels were not observed in any filtered water samples taken from the chamber with the UV unit during the study. Juveniles were however, observed in the filtered water samples taken from the control tank on four occasions.

Since the lamp was placed directly into the settling chamber, post exposure contact time is not applicable for this test apparatus. The purpose of this study was not to determine the feasibility of downstream settlement prevention. 

The single low pressure UV lamp in the open channel was very effective at preventing zebra mussel attachment to the walls of the tank.

Mortality rates were not as high in settling chamber effluent samples as were found in the two low pressure mercury lamp flow through systems. Since this sample was taken directly from the effluent immediately following exposure to the constantly irradiated contact/settlement chamber, latent effects of exposure are not seen, which may be influencing the relative viable proportion of larvae in this test system.

Because the UV lamp was not situated in a central position perfectly parallel to flow in the tank (Figure 10), the relative intensities of UV exposure differed throughout the tank. The average intensity in the water column between the UV lamp and the furthest point in the tank was $13,400 \mu \mathrm{W} / \mathrm{cm}^{2}$. The average intensity between the lamp and the walls parallel to the lamp was $15,700 \mu \mathrm{W} / \mathrm{cm}^{2}$. The UV intensity at the furthest point $(19.5 \mathrm{~cm})$ from the lamp was $1,900 \mu \mathrm{W} / \mathrm{cm}^{2}$ which was 3.8 times that of the batch tests. It may be that an effective intensity threshold is present above $1,900 \mu \mathrm{W} / \mathrm{cm}^{2}$, which would explain the presence of juveniles on the tank wall at this location, as well as limited effectiveness of the low pressure lamp in batch UV tests.

\subsubsection{4) Single Lamp - Medium Pressure System (365 nm)}

Total post veliger densities and relative viable proportions in effluent samples for the single lamp medium pressure system and its control are shown in Figures 16-1 and 16-2.

Post veliger densities in the settling chamber effluent for the test system were observed to be $<2,000 / \mathrm{m}^{3}$ in most of the samples. However, two peaks of approximately $4,000 / \mathrm{m}^{3}$ were detected in samples taken on July 16 and October 12 (Figure 16-2).

Total post veliger densities in samples taken from the control tank effluent in July were considerably higher than those observed in the test system effluent. On three of the sampling dates, densities were observed to be $6,000-8,000 / \mathrm{m}^{3}$. Total post veliger densities in the control 

tank over the remainder of the study period do not appear to be significantly different than those observed in the UV system effluent. (Figure 16-1).

The concentration of post veligers in settling chamber effluent samples taken from the medium pressure test system were on the average higher than those observed with the low pressure mercury lamps.

The relative proportion of viable post veligers was dramatically reduced in the test system relative to the control. The relative proportion of viable post veligers observed in the control tank was less than $80 \%$ on most occasions, while in the test tank, the relative proportion was usually less than $50 \%$ and on a number of occasions $0 \%$.

The proportion of viable to non-viable post veligers in the medium pressure system was similar to that observed with the single low pressure mercury lamp but considerably higher than the UV system with multiple low pressure mercury lamps.

It can be seen that as the flow rates were increased in September and October, the relative number of viable larvae detected in the effluent increased although this did not affect settlement in the chamber. This trend corresponds to the multi-lamp system and open channel system which both had shorter retention times with less time between UV exposure and sampling. It may be that a critical post exposure time is necessary before damage by UV exposure causes mortality, or that increased flows resulted in a lower dose to the organisms and therefore lower short term mortality. Continued lack of settlement indicates that latent mortality remains high.

Low juvenile densities were observed in filtered water samples taken from the settling chamber downstream of the UV unit on two sampling dates during the study. On both occasions these observations consisted of empty shells and were not likely an indication of mussel settlement, but rather debris that had passed through the test apparatus.

Based on a flow rate of $6 \mathrm{~L} /$ minute, the post exposure contact time in the settling chamber was estimated to be 4.5 minutes. The contact time was reduced to 2.7 minutes when the flow was 

increased to $10 \mathrm{~L} /$ minutes in September and further reduced to 1.8 minutes when the flow was increased to $15 \mathrm{~L} /$ minute in October.

Culture plates were not available for this system, however the results of tank wall scrapings are presented in Section 4.3.3.

\subsection{3) Post Study Tank Wall and Culture Plate Settlement}

The tank walls and culture plates downstream of each UV unit and in controls were scraped at the conclusion of the study to determine the effectiveness of each UV system in preventing downstream settling and growth of juvenile mussels.

\subsubsection{1) Single Lamp - Low Pressure System}

The UV system with a single low pressure mercury lamp was effective in minimizing juvenile settlement in the downstream settling chamber. These results are comparable to those previously mentioned in the Ontario Hydro study.

Scrapings from the inlet and outlet wall of the chamber indicated that no juveniles were able to settle in these areas. In contrast, juvenile densities of $1,400 / \mathrm{m}^{2}$ were observed on the inlet wall and $3,400 / \mathrm{m}^{2}$ were observed on the outlet wall of the control chamber (Figure 17).

Scrapings from the culture plates in the test system indicated a similar trend, although low juvenile densities of $22 / \mathrm{m}^{2}$ and $130 / \mathrm{m}^{2}$ were observed on plates 1 and 6 respectively.

Settled juvenile mussels were observed on all of the culture plates in the control tank at the end of the study. Densities ranged from lows of $10 / \mathrm{m}^{2}$ to highs of $2,000-3,000 / \mathrm{m}^{2}$ (Figure 17). 

The multiple lamp - low pressure UV system was almost completely effective in preventing juvenile settlement.

Scrapings taken from the outlet wall of the chamber downstream of the UV unit indicated that a very low density $\left(44 / \mathrm{m}^{2}\right)$ of juveniles had settled in this area. No juveniles were observed on the inlet wall at the end of the study (Figure 18).

No juveniles were observed on any of the culture plates in the test system at the end of the study. Juveniles were present on all culture plates in the control chamber. Densities ranged from 800 $2,500 / \mathrm{m}^{2}$ (Figure 18).

\subsubsection{3) Open Channel - Low Pressure System}

The open channel - low pressure UV system was effective in inhibiting juvenile settlement in the downstream contact/test chamber.

The culture plates which are used to determine mussel settlement rates were not in place for the test and control chambers for this UV system due to the placement of the lamp in the chamber. As a result, scrapings at the end of the study were taken from the inlet and outlet walls as well as the left and right side walls and juvenile densities were determined.

Juveniles were observed to be present only on the inlet wall of the test chamber. A density of $109 / \mathrm{m}^{2}$ juveniles was observed in this sample. No juveniles were observed on the outlet, left or right side walls, (Figure 19).

It should be noted that the settled mussels were detected in the zone which was furthest from the UV lamp source and therefore received the lowest intensity of UV irradiation, $\left(1,900 \mu \mathrm{W} / \mathrm{Cm}^{2}\right)$. Juveniles were present in the scrapings from all four walls of the control chamber. Densities 


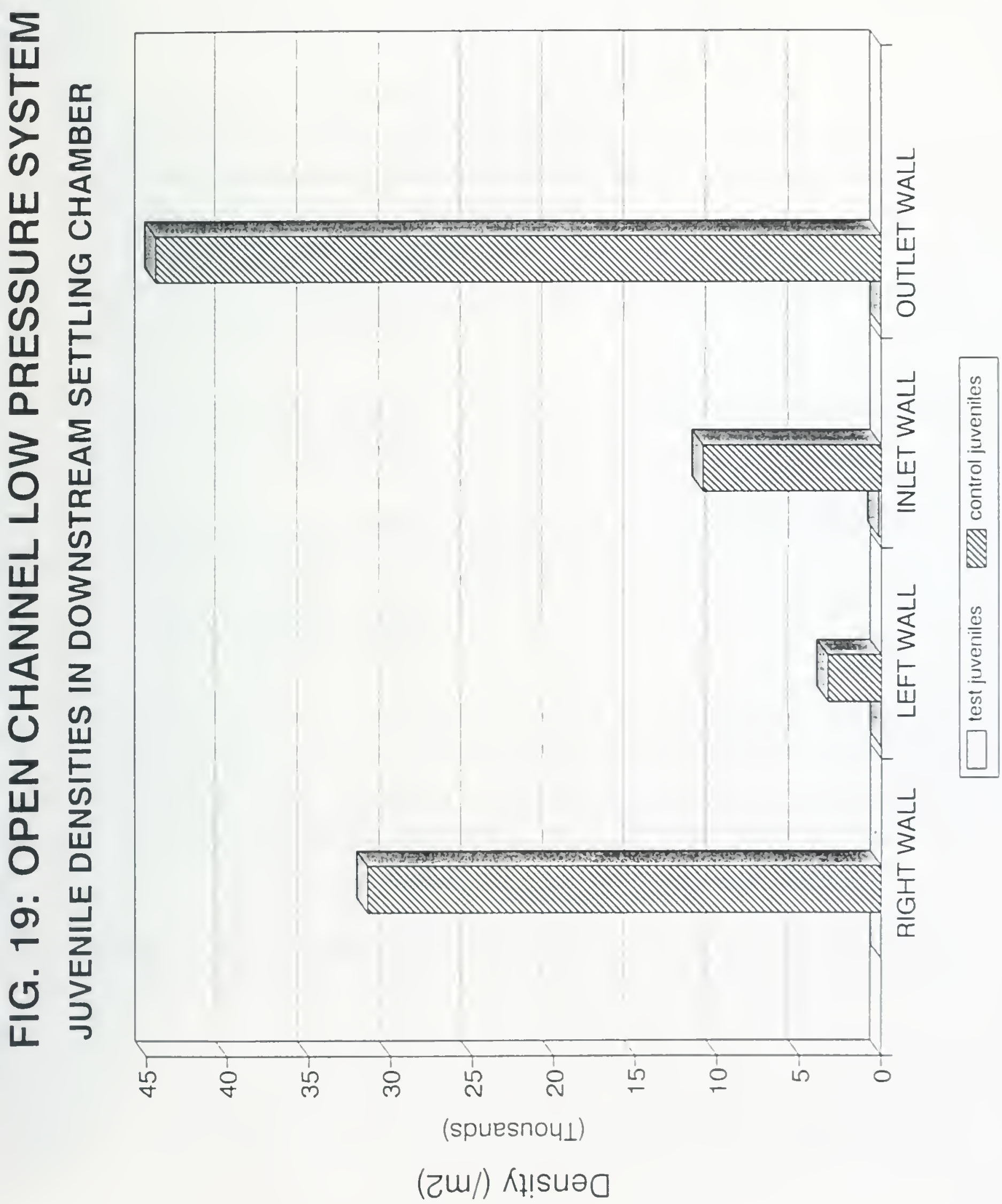

observed were: $10,000 / \mathrm{m}^{2}$ on the inlet wall; $31,000 / \mathrm{m}^{2}$ on the right side wall, $3,200 / \mathrm{m}^{2}$ on the left side wall, and $44,000 / \mathrm{m}^{2}$ on the outlet wall, (Figure 19).

\subsubsection{4) Single Lamp - Medium Pressure System}

The single lamp - medium pressure system was completely effective in preventing settlement of juvenile mussels.

Culture plates were not available for this UV system and the same methodologies used to sample the open channel system were performed.

Juveniles were not observed in scrapings from the walls of the downstream settling chamber for the UV system with the medium pressure mercury lamp, (Figure 20).

Settled juveniles were observed in the scrapings from all four walls in the control chamber. Densities ranged from $3,200 / \mathrm{m}^{2}$ up to $44,000 / \mathrm{m}^{2}$, (Figure 20 ).

\subsubsection{5) Five Day Sediment Analysis}

Previous research completed by Aquatic Sciences Inc. on the use of oxidants for control of mussels showed that a phenomenon known as inactivation occurs, whereby larvae in the post veliger stage detect the toxic agent and close their valves. At this point these heavier larvae settle, through the process of sedimentation, because they can no longer use cilia to maintain themselves in the water column.

A five-day trial was run to determine whether the same process was occurring with UV treatment, thus resulting in lower post veliger numbers in test tank effluents as opposed to controls.

The results verify this phenomena and in the case of the medium pressure lamp. much greater numbers of post veligers were detected in sediment from test tanks when compared to controls (Figure 21). Although this trend was not observed in the low pressure system (Figure 22), the test 



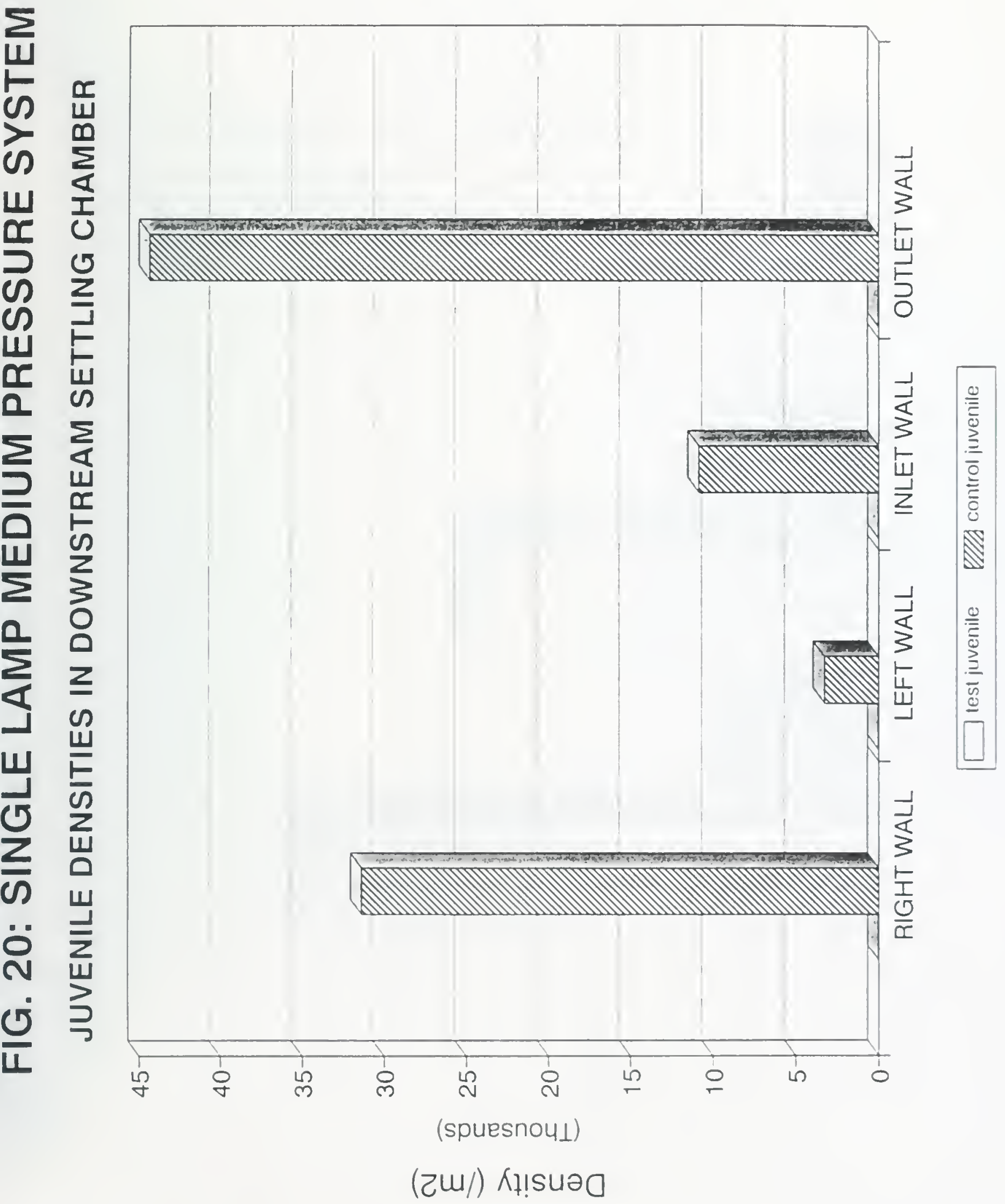





$$
\text { ह }
$$




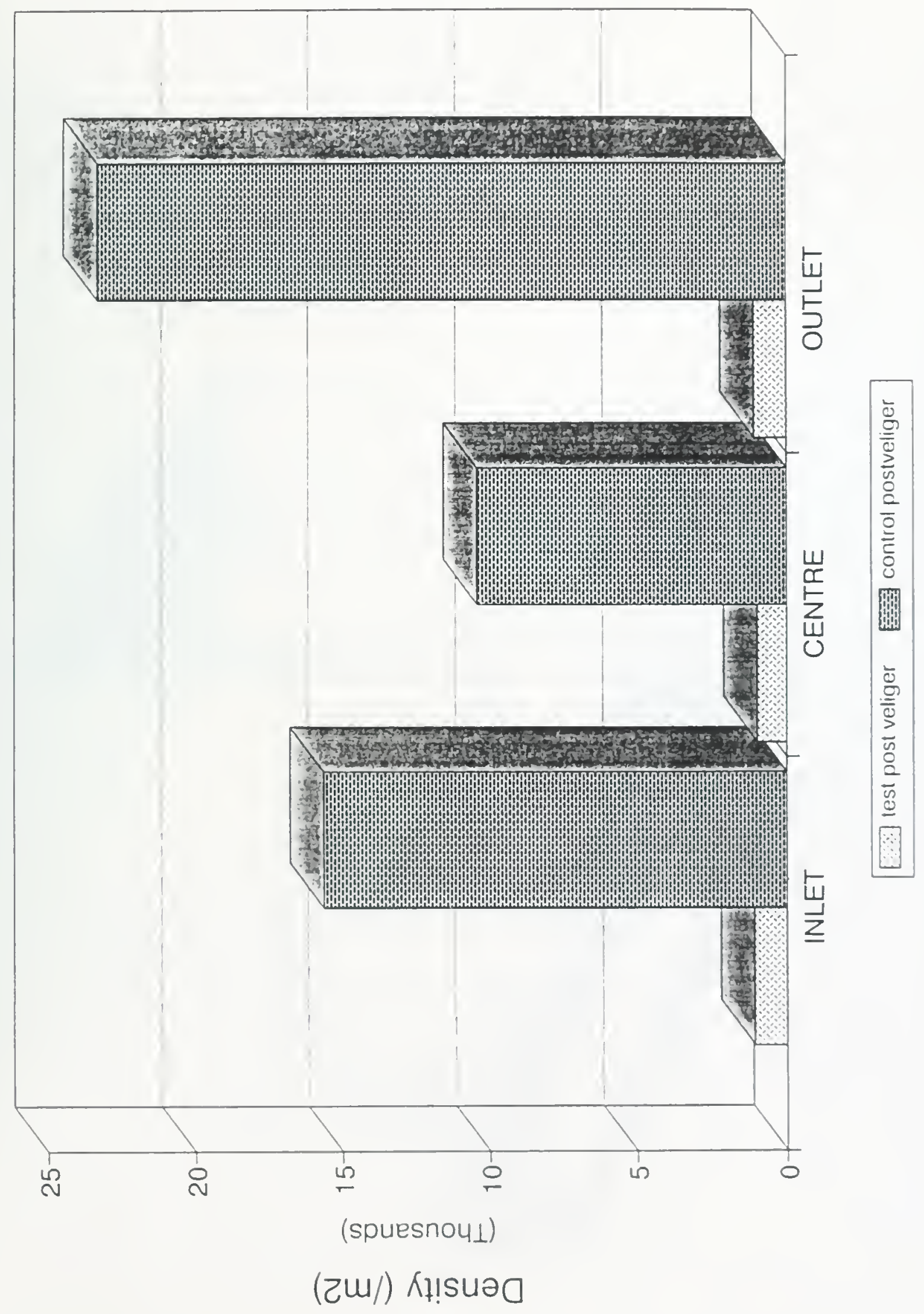




$$
E
$$



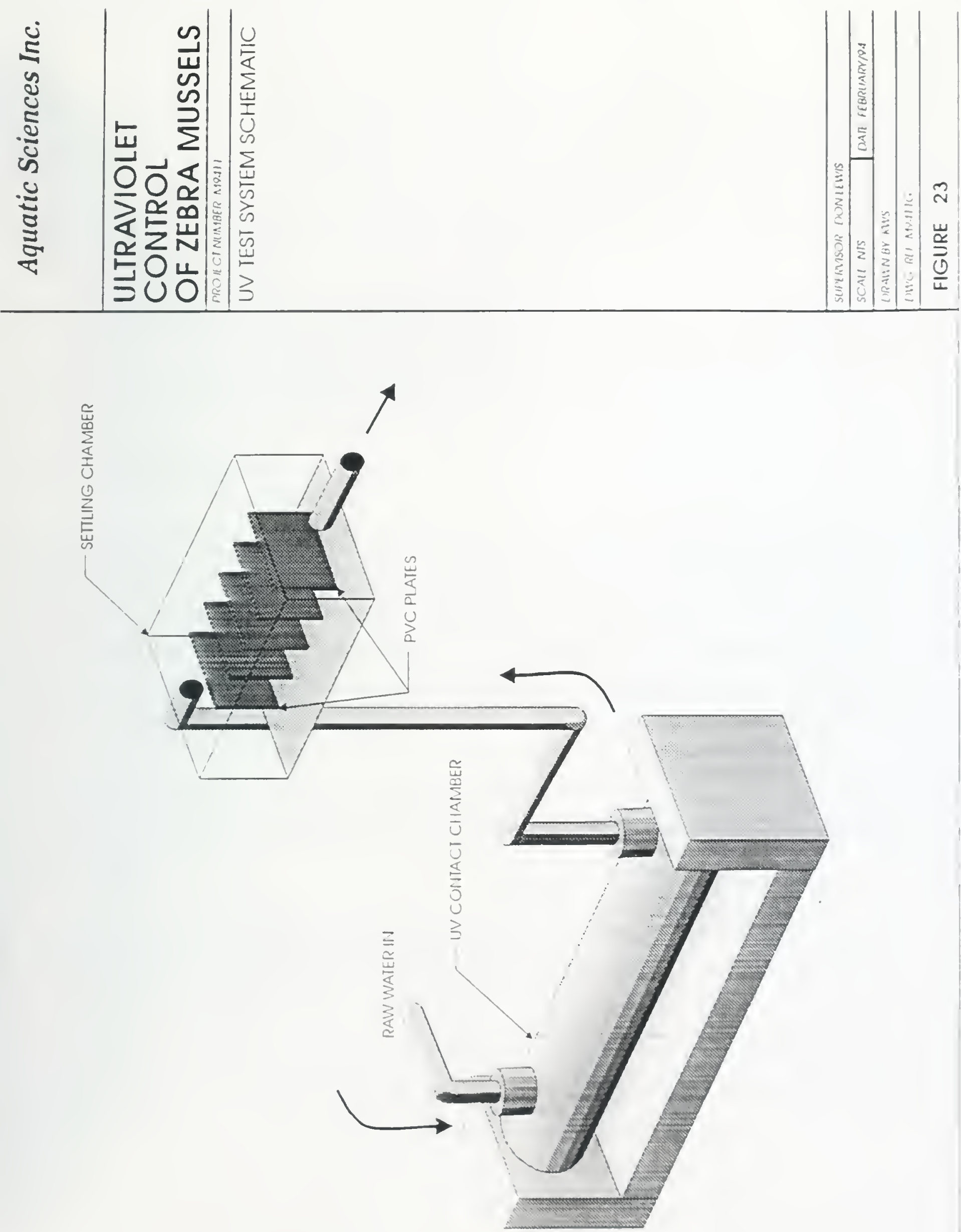

system configuration for this particular UV system included a $1.5 \mathrm{~m}$ rise from floor to table top (Figure 23) prior to entering the settling chamber. It is speculated that inactivated mussels settled in significant numbers at the base of this rise prior to entering the settlement chamber, therefore reducing the numbers of veligers that entered the chamber and were ultimately found in the sediment.

This test gives some indication that the effect on larvae is almost immediate. It may be that the UV exposure is impairing swimming ability and ultimately causing mortality. All larvae found in sediments downstream of UV exposure after this study were dead.

\section{4) Phase II Conclusions}

The results of Phase I batch tests do not appear to have told the whole story with regard to UV control of zebra mussels. The only obvious difference between Phase I and Phase II was the intensity of ultraviolet light. In batch tests, the UV intensity may have been below a threshold where most of the UV light is absorbed by non-critical, easily repaired components in the cells of the zebra mussel before reaches the DNA. The increased intensity in the flow through tests resulted in higher mortalities with lower doses of UV light which would support this hypothesis.

The degree of viability of post veligers immediately after UV irradiation did not appear to have any effect on the numbers of attached mussels found on the surfaces of the settling chambers and culture plates.

Tests at higher flow rates gave indications that immediate mortality may not be the only mechanism at work controlling infestation rates of downstream surfaces.

All of the UV systems were effective in preventing zebra mussel attachment and growth on downstream surfaces. This phenomenon is the main characteristic that makes zebra mussel infestation a serious impairment to water users. 

The choice of low or medium pressure mercury lamps for control of downstream zebra mussel settlement would be dependent upon the particular application. Physical and chemical characteristics of the water, such as high organic content or turbidity, as well as higher system flow would dictate a movement towards the longer effective wavelengths of the medium pressure lamp. Both systems seem to have significant impact on mussel settlement.

To prevent the attachment of zebra mussels to surfaces, it may suffice to hang UV lamps in the water or attach them in a close proximity to surfaces to be protected.

Curtains of UV lamps could be used to prevent the attachment of zebra mussels to water intake and piping systems.

Further study is necessary to determine the lowest effective intensities and contact times for mussel control. This work will allow engineering of cost effective control systems for wide spread use. 



\section{0) RECOMMENDATIONS}

1. A study should be completed to determine the effect of higher flow rates per arc of UV lamp on the attachment of zebra mussels to surfaces. This will provide a proper comparison between UV irradiation and chemical methods for control of zebra mussels in working water intake systems.

2. A full scale UV system should be built and tested to determine whether this technology is applicable to the flow rates in electrical power plants or major industries.

3. The limiting factors (an interaction), i.e. dose of UV and intensity should be further examined using batch testing to provide more accurate information on the delivery of UV energy required for design of test systems.

4. The mode of action of UV light on effecting inhibition of colonization should be investigated further, including the role of biofilm development and the longer term effects on larval mussel growth and eventual reproduction. 

APPENDIX I 



\section{EFFECT OF UV IRRADIATION OF HETEROTROPHIC MICROORGANISMS}

\section{METHODS}

The heterotrophic plate count was done by the membrane filtration method using m-HPC agar according to Standard Method for the Examination of Water and Wastewater, 18th Edition.

Influent and effluent samples were obtained as close as possible to the inlets or outlets of the UV units to eliminate the effect of microorganisms sloughing off the piping.

The samples were kept on ice in the dark until they were analyzed to prevent photo-reaction or growth.

The analysis was conducted by the Ontario Ministry of the Environment and Energy in London, Ontario.

The experiment was done once and the counts were done in duplicate. 



\section{RESULTS ANI) DISCUSSION}

Table 3: Heterotrophic plant count before and after the UV units

Sample Source

Geometric Mean

Counts/ml

Single Medium Pressure

Influent

4,900

Mercury Lamp

Effluent

Multi-Lamp Low Pressure

Influent

23,000

Mercury Lamps

Effluent

Single-Lamp Low Pressure

Influent

48,000

Mercury Lamp

Effluent

UV Lamp in the Open Channel Influent

The UV systems reduced the heterotrophic plate count in the lake water. It is interesting that this is consistent with the hypothesis that the absence of biofilm could be inhibiting mussel settlement downstream.

Due to the lack of enough data, it is impossible to conclusively determine the effect of UV dose on the kill of the heterotrophic microorganisms. The UV dose from the UV unit with eight low pressure mercury lamps was far in excess of that with the one low pressure mercury lamp but the kill of the heterotrophic microorganisms was smaller.

This experiment would need significant replication to provide convincing data. 



\section{REFERENCES}

1. Chalker-Scott, L. J. Scott, J. Scalia, J. Titus, 1994, Influences of Wide Range Ultraviolet Radiation Upon Behaviour and Mortality of Dreissena polymorpha, 4th International Zebra Mussel Conference, Madison, Wisconsin, 1994.

2. Qualls, R.G. and J.D. Johnson, 1983. "Bioassay and Dose Measurement in UV Disinfection". Applied and Environmental Microbiology, 45:872-877. 

